\title{
Observations and simulation of intense convection embedded in a warm conveyor belt - how ambient vertical wind shear determines the dynamical impact
}

\author{
Annika Oertel ${ }^{1,2}$, Michael Sprenger ${ }^{1}$, Hanna Joos ${ }^{1}$, Maxi Boettcher ${ }^{1}$, Heike Konow ${ }^{3}$, Martin Hagen ${ }^{4}$, and \\ Heini Wernli ${ }^{1}$ \\ ${ }^{1}$ Institute for Atmospheric and Climate Science, ETH Zürich, Zürich, Switzerland \\ ${ }^{2}$ Institute of Meteorology and Climate Research (IMK-TRO), Karlsruhe Institute of Technology (KIT), Karlsruhe, Germany \\ ${ }^{3}$ Meteorological Institute, University of Hamburg, Hamburg, Germany \\ ${ }^{4}$ Institute of Atmospheric Physics, Deutsches Zentrum für Luft- und Raumfahrt, Oberpfaffenhofen, Germany
}

Correspondence: Annika Oertel (annika.oertel@kit.edu)

Received: 29 September 2020 - Discussion started: 9 October 2020

Revised: 13 January 2021 - Accepted: 15 January 2021 - Published: 2 February 2021

\begin{abstract}
Warm conveyor belts (WCBs) are dynamically important, strongly ascending and mostly stratiform cloudforming airstreams in extratropical cyclones. Despite the predominantly stratiform character of the WCB's large-scale cloud band, convective clouds can be embedded in it. This embedded convection leads to a heterogeneously structured cloud band with locally enhanced hydrometeor content, intense surface precipitation and substantial amounts of graupel in the middle troposphere. Recent studies showed that embedded convection forms dynamically relevant quasihorizontal potential vorticity (PV) dipoles in the upper troposphere. Thereby one pole can reach strongly negative PV values associated with inertial or symmetric instability near the upper-level PV waveguide, where it can interact with and modify the upper-level jet. This study analyzes the characteristics of embedded convection in the WCB of cyclone Sanchez based on WCB online trajectories from a convection-permitting simulation and airborne radar observations during the North Atlantic Waveguide and Downstream Impact Experiment (NAWDEX) field campaign (intense observation periods, IOPs, 10 and 11). In the first part, we present the radar reflectivity structure of the WCB and corroborate its heterogeneous cloud structure and the occurrence of embedded convection. Radar observations in three different sub-regions of the WCB cloud band reveal the differing intensity of its embedded convection, which is qualitatively confirmed by the ascent rates of the online WCB
\end{abstract}

trajectories. The detailed ascent behavior of the WCB trajectories reveals that very intense convection with ascent rates of $600 \mathrm{hPa}$ in $30-60 \mathrm{~min}$ occurs, in addition to comparatively moderate convection with slower ascent velocities as reported in previous case studies. In the second part of this study, a systematic Lagrangian composite analysis based on online trajectories for two sub-categories of WCBembedded convection - moderate and intense convection - is performed. Composites of the cloud and precipitation structure confirm the large influence of embedded convection: intense convection produces very intense local surface precipitation with peak values exceeding $6 \mathrm{~mm}$ in $15 \mathrm{~min}$ and large amounts of graupel of up to $2.8 \mathrm{~g} \mathrm{~kg}^{-1}$ in the middle troposphere (compared to $3.9 \mathrm{~mm}$ and $1.0 \mathrm{~g} \mathrm{~kg}^{-1}$ for the moderate convective WCB sub-category). In the upper troposphere, both convective WCB trajectory sub-categories form a smallscale and weak PV dipole, with one pole reaching weakly negative PV values. However, for this WCB case study in contrast to previous case studies reporting convective PV dipoles in the WCB ascent region with the negative PV pole near the upper-level jet - the negative PV pole is located east of the convective ascent region, i.e., away from the upperlevel jet. Moreover, the PV dipole formed by the intense convective WCB trajectories is weaker and has a smaller horizontal and vertical extent compared to a previous NAWDEX case study of WCB-embedded convection, despite faster ascent rates in this case. The absence of a strong upper-level jet 
and the weak vertical shear of the ambient wind in cyclone Sanchez are accountable for the weak diabatic PV modification in the upper troposphere. This implies that the strength of embedded convection alone is not a reliable measure for the effect of embedded convection on upper-level PV modification and its impact on the upper-level jet. Instead, the profile of vertical wind shear and the alignment of embedded convection with a strong upper-level jet play a key role for the formation of coherent negative PV features near the jet. Finally, these results highlight the large case-to-case variability of embedded convection not only in terms of frequency and intensity of embedded convection in WCBs but also in terms of its dynamical implications.

\section{Introduction}

Convective storms form an important part of the climate system (Houze, 1973) and still constitute one of the major obstacles for the improvement of weather and climate predictions (e.g., Ban et al., 2014; Sherwood et al., 2014; Holloway et al., 2014). In contrast to the well-studied so-called isolated and often tropical convection, convective clouds in the mid-latitudes can be an integral part of larger-scale weather systems. In the extratropical storm track region, convective clouds can be embedded within larger-scale cloud bands of extratropical cyclones (e.g., Browning et al., 1973; Browning and Roberts, 1999; Neiman et al., 1993; Naud et al., 2015; Flaounas et al., 2016), resulting in mesoscale variability of the cloud and precipitation structure. Recent studies also corroborated the occurrence of convection embedded in the warm conveyor belt (WCB) airstream (Binder, 2016; Crespo and Posselt, 2016; Rasp et al., 2016; Flaounas et al., 2016, 2018; Oertel et al., 2019, 2020; Blanchard et al., 2020) as originally proposed by Neiman et al. (1993) in their socalled "escalator-elevator" concept. In the classical perspective, the WCB (e.g., Browning, 1990; Madonna et al., 2014) is described as a gradually ascending and mostly stratiformcloud-forming airstream in extratropical cyclones. Its slantwise ascending motion has been referred to as "escalator"like ascent. In contrast, the phases of rapid convective ascent embedded within this large-scale airstream were referred to as the "elevator".

The convective activity can be directly embedded within the large-scale WCB cloud band and is characterized by a locally denser cloud with enhanced hydrometeor content and enhanced surface precipitation intensity (Oertel et al., 2019, 2020). From an observational perspective, WCBembedded convection is typically "hidden" within the largescale cloud band of the WCB. In radar observations it has been identified through increased horizontal heterogeneity of the radar reflectivity, the absence of a well-defined bright band and the occurrence of narrow plumes of enhanced radar reflectivity (Neiman et al., 1993; Crespo and Posselt,
2016; Oertel et al., 2019). Compared to deep convective storms, where reflectivities exceed $40-50 \mathrm{dBZ}$ in the upper troposphere and updrafts exceed $10-15 \mathrm{~m} \mathrm{~s}^{-1}$ (e.g., Carbone, 1982; Miller et al., 1988; Steiner et al., 1995), the ascent within embedded convection was reported to be slower with $1-5 \mathrm{~m} \mathrm{~s}^{-1}$ with radar reflectivities reaching approximately 20-30 dBZ (Crespo and Posselt, 2016; Oertel et al., 2019; Binder et al., 2020; Gehring et al., 2020; Blanchard et al., 2020).

It is well known that WCBs are dynamically relevant airstreams in extratropical cyclones that can modify the larger-scale flow evolution during their ascent from the boundary layer into the upper troposphere (e.g., Grams et al., 2011; Binder et al., 2016; Joos and Forbes, 2016; Rodwell et al., 2017). Their impact on the upper-tropospheric flow can be conveniently analyzed with the potential vorticity (PV) framework (Hoskins et al., 1985) because the intense cloud diabatic processes during their deep ascent distinctly modify the PV distribution, typically leading to a wide region of low-PV air in the upper tropospheric ridge (e.g., Wernli and Davies, 1997; Pomroy and Thorpe, 2000; Madonna et al., 2014; Methven, 2015). Harvey et al. (2020) and Oertel et al. (2020) showed that smaller-scale regions of strongly enhanced diabatic heating, such as from convective ascent, embedded in this large-scale WCB ascent region can form quasi-horizontal upper-level PV dipoles with a positive PV pole to the east towards the ridge, and a region of negative PV to the west near the upper-level PV waveguide. The latter can be relevant for the upper-level jet structure and the largerscale flow evolution. The smaller-scale and narrow regions of increased hydrometeor production associated with the locally confined regions of embedded convective ascent lead to strong horizontal diabatic heating gradients $\left(\nabla_{\mathrm{h}} \dot{\theta}\right)$, which are substantially stronger than for a purely slantwise ascending WCB that forms an extended region of moderate heating. This subsequently influences the resulting PV signature (Hoskins et al., 1985):

$$
\frac{\mathrm{D}}{\mathrm{D} t} \mathrm{PV}=\frac{1}{\rho} \boldsymbol{\omega} \cdot \nabla \dot{\theta}=\frac{1}{\rho}\left[(f+\zeta) \frac{\partial \dot{\theta}}{\partial z}+\omega_{\mathrm{h}} \cdot \nabla_{\mathrm{h}} \dot{\theta}\right],
$$

where PV is defined as (Ertel, 1942)

$$
\mathrm{PV}=\frac{1}{\rho} \omega \cdot \nabla \theta
$$

and $\rho$ is density, $\theta$ is potential temperature, $\dot{\theta}$ represents latent heating or cooling, and $\omega$ is $3 \mathrm{D}$ absolute vorticity defined as

$$
\boldsymbol{\omega}=\nabla \times \boldsymbol{u}+2 \boldsymbol{\Omega}=\xi \mathbf{i}+\eta \mathbf{j}+(f+\zeta) \mathbf{k} .
$$

Thereby, $\boldsymbol{u}$ is the 3D wind vector, $\boldsymbol{\Omega}$ is the vector of earth rotation, $\xi$ and $\eta$ are the horizontal vorticity components in 
$x$ and $y$ directions, $f$ is the Coriolis parameter, $f+\zeta$ is the absolute vertical vorticity, and $\omega_{\mathrm{h}}$ denotes the horizontal vorticity $\left(\omega_{\mathrm{h}}=\xi \mathbf{i}+\eta \mathbf{j}\right)$.

Scale analysis shows that the vertical components of Eq. (1) (first term) are dominant on large scales (such as WCB ascent with length scales of the order of $10^{6} \mathrm{~m}$, where $R o \ll 1$, with the Rossby number $R o=\frac{U}{f \cdot L}$ ), whereas for smaller length scales such as convection $(R o>1)$ the horizontal components (second term in Eq. 1) become increasingly important (Haynes and McIntyre, 1987; MartínezAlvarado et al., 2016; Harvey et al., 2020). The latter also applies if the length scale of diabatic heating occurs on a smaller spatial scale than the large-scale flow, as for example for localized heating embedded in the large-scale WCB ascent (Harvey et al., 2020). Idealized simulations (Chagnon and Gray, 2009) show a gradual tilt from a vertically oriented PV dipole - where $(f+\zeta) \frac{\partial \dot{\theta}}{\partial z}$ dominates - to a horizontally oriented PV dipole - where $\omega_{\mathrm{h}} \cdot \nabla_{\mathrm{h}} \dot{\theta}$ becomes increasingly important - with a decrease in the scale of the system and an increase in the environmental wind shear.

As a consequence, the typical large-scale and slantwise WCB ascent forms predominantly a vertical PV dipole (Eq. 1, first term) with increased low-level PV and a widespread region of low-PV air in the upper troposphere (e.g., Wernli and Davies, 1997; Joos and Wernli, 2012; Madonna et al., 2014). In contrast, convection in a vertically sheared environment forms quasi-horizontal mid-level to upper-level PV dipoles that are centered around the convective updraft with the negative PV pole to the left of the vertical wind shear vector and the positive PV pole to the right of the vertical wind shear vector (Eq. 1, second term). The formation of such quasi-horizontal PV dipole structures have been found in idealized simulations of isolated cumulus-scale convection (Chagnon and Gray, 2009), in case studies of mesoscale convective systems (Davis and Weisman, 1994; Chagnon and Gray, 2009; Hitchman and Rowe, 2017; Clarke et al., 2019), in mid-latitude convective updrafts with varying large-scale flow conditions (Weijenborg et al., 2015, 2017; Müller et al., 2020), and embedded in the baroclinic WCB ascent region (Harvey et al., 2020; Oertel et al., 2020). These PV anomalies can reach a magnitude of $\pm 10 \mathrm{PVU}$ and hence exceed the typical range of synopticscale PV.

The convective-scale PV anomalies are dynamically relevant as they are associated with mesoscale circulation anomalies (Oertel et al., 2020; Oertel and Schemm, 2020) and can interact with the larger-scale flow (Clarke et al., 2019; Harvey et al., 2020; Oertel et al., 2020). Oertel et al. (2020) and Harvey et al. (2020) showed that convective activity and narrow bands of strong latent heating embedded in the baroclinic region ahead of an upper-level trough can form elongated bands of negative PV at the jet-facing side of the heating region. These negative PV bands strengthen the isentropic PV gradient across the tropopause and are associated with an accelerated upper-level jet. Hence, in certain synoptic situations, the dynamically unstable ${ }^{1}$ region of convectively formed negative PV and its associated anticyclonic absolute vertical vorticity can become relevant as it interacts with and modifies the upper-level PV waveguide (Harvey et al., 2020; Oertel et al., 2020).

Although recent case studies have corroborated the presence of embedded convection in WCBs (Rasp et al., 2016; Crespo and Posselt, 2016; Flaounas et al., 2016, 2018; Oertel et al., 2019), several major issues are still uncertain: (i) where and how often is convection generally embedded in the WCB ascent region? (ii) How variable is the strength of embedded convection in WCBs? (iii) Does WCB-embedded convection consistently form coherent PV dipoles with the negative pole in the vicinity of the upper-level jet (as shown in the previous case study by Oertel et al., 2020)?

While the first point requires a climatological analysis of embedded convection, here we specifically address the variable strength and dynamical signatures of embedded convection in a specific WCB. The aim of this detailed WCB case study is two-fold: on the one hand, we corroborate the concept of embedded convection in WCBs and identify WCBembedded convection with differing strengths based on rare airborne radar observations of a WCB and online trajectories in a convection-permitting simulation. On the other hand, we systematically analyze the characteristics and the PV signature associated with (i) intense and (ii) moderate WCBembedded convection. Therefore, we investigate the WCB associated with the surface cyclone and upper-level PV cutoff Sanchez that occurred during the North Atlantic Waveguide and Downstream Impact Experiment (NAWDEX, Schäfler et al., 2018) field campaign.

Specifically, we address the following questions:

1. What do airborne radar observations of the WCB cloud band in cyclone Sanchez reveal about the strength of embedded convective activity (Sect. 4)?

2. What are the (thermodynamic) characteristics associated with WCB-embedded convection in this case study (Sect. 5.3 and 5.4)?

3. How important is the strength of WCB-embedded convection for the resulting upper-level PV modification compared to characteristics of the ambient flow (Sect. 5.5 and 5.6)?

This study is structured in the following way: after introducing the data and methodology (Sect. 2) and presenting the evolution of the WCB and its embedded convection (Sect. 3),

\footnotetext{
${ }^{1}$ Negative PV values in the Northern Hemisphere are related to hydrostatic, inertial or symmetric instability (e.g., Hoskins, 2015) and have been associated with mesoscale circulations (e.g., Bennetts and Hoskins, 1979; Schultz and Schumacher, 1999; Volonté et al., 2020).
} 
the first part of the results (Sect. 4) shows the radar-based perspective of the WCB cloud band and qualitatively compares the observations with online trajectories from a convectionpermitting simulation. In the second part (Sect. 5), we perform a 3D Lagrangian composite analysis to investigate the PV modification by two categories of convective WCB trajectories - intensely and more moderately ascending convective WCB trajectories. Throughout this study, results are compared with cyclone Vladiana, a previous case study of WCB-embedded convection, which also occurred over the North Atlantic during the NAWDEX field campaign 2 weeks earlier (Oertel et al., 2020).

\section{Data}

\subsection{Airborne radar observations}

The investigated cyclone Sanchez occurred in October 2016 during the NAWDEX field campaign (IOPs 10 and 11, Schäfler et al., 2018). During this campaign the German research aircraft HALO (High Altitude and LOng Range Research Aircraft) observed the cloud structure of the cyclone and its associated WCB twice on two consecutive days. The research aircraft carries the HALO Microwave Package (HAMP), which includes the high-sensitivity cloud radar MIRA-36 (Melchiona et al., 2008; Mech et al., 2014). The downward-pointing Doppler radar operates at a frequency of $35.5 \mathrm{GHz}$ and reaches an expected airborne sensitivity of $-38 \mathrm{dBZ}$ at $5 \mathrm{~km}$ distance (Mech et al., 2014), which reduces to $\approx-30 \mathrm{dBZ}$ at $13 \mathrm{~km}$ distance (Konow et al., 2019). The measured along-flight radar reflectivity $Z$ has been postprocessed, offset-corrected and corrected for aircraft attitude (Ewald et al., 2019; Konow et al., 2019) and is obtained from Konow et al. (2018).

To characterize the large-scale cloud band of the WCB and its embedded convection we analyze the radar reflectivity structure where the HALO flight track intersects the WCB cloud band. The location of WCB air parcels is determined by the operational analyses from the ECMWF (see Sect. 2.2). The radar reflectivity structure of convective clouds is relatively heterogeneous compared to homogeneous stratiform clouds (e.g., Steiner et al., 1995) and often appears as confined towers (Hogan et al., 2002; Murphy et al., 2017). Here, we visually identify convective regions, where narrow plumes of increased values of $Z$ rise above the $0^{\circ} \mathrm{C}$ isotherm (see Hogan et al., 2002; Murphy et al., 2017; Oertel et al., 2019). Further applied indications for convective activity are locally enhanced radar reflectivity, a broken cloud top, spatially heterogeneous cloud top height and the absence of a pronounced radar bright band.

\subsection{Offline WCB trajectories from ECMWF analyses}

The large-scale WCB ascent region is identified with offline trajectories from the operational analyses from the Inte- grated Forecasting System (IFS) of the European Centre for Medium-Range Weather Forecasts (ECMWF), which is run with a spatial resolution of approximately $9 \mathrm{~km}$ with 137 vertical hybrid pressure-sigma levels - operational model version in October 2016 (cycl 41r2, ECMWF, 2016) - and includes parameterized shallow and deep convection (Tiedtke, 1989; Bechtold et al., 2008, 2014). The trajectories are computed with the Lagrangian analysis tool LAGRANTO (Wernli and Davies, 1997; Sprenger and Wernli, 2015) from 1 -hourly $3 \mathrm{D}$ wind fields that are interpolated to a regular $0.5^{\circ}$ grid and combine 3-hourly analyses with operational shortterm forecasts in between. To identify the WCB, trajectories were started globally every hour and every $80 \mathrm{~km}$ in the horizontal on 14 vertical levels (every $25 \mathrm{hPa}$ between 1025 and $700 \mathrm{hPa}$ ) similar to the method applied in Madonna et al. (2014). WCB trajectories are subsequently selected as trajectories with ascent rates of at least $600 \mathrm{hPa}$ in $48 \mathrm{~h}$ (e.g., Madonna et al., 2014).

\subsection{Convection-permitting simulation and online WCB trajectories}

To simulate the WCB and its embedded convection, we use the fully elastic nonhydrostatic limited-area model COSMO (Consortium for Small-scale Modeling; Baldauf et al., 2011; Doms and Baldauf, 2018). The domain is centered in the eastern North Atlantic and extends from about $55^{\circ} \mathrm{W}$ to $5^{\circ} \mathrm{E}$ and 30 to $65^{\circ} \mathrm{N}$ (e.g., Fig. $1 \mathrm{j}$ ). The simulation is run in convection-permitting mode with a horizontal grid-spacing of $0.02^{\circ}(\sim 2.2 \mathrm{~km})$ and with 60 vertical levels. We employed a one-moment six-category cloud microphysics scheme including prognostic water vapor $\left(q_{\mathrm{v}}\right)$, liquid (LWC) and ice (IWC) cloud water content, rain (RWC), snow (SWC) and graupel (GWC), which is important for the explicit simulation of deep convection (Baldauf et al., 2011). While deep convection is treated explicitly at $2.2 \mathrm{~km}$ (e.g., Ban et al., 2014), we applied the reduced Tiedtke scheme for shallow convection (Tiedtke, 1989; Baldauf et al., 2011). 3D COSMO fields were output every $15 \mathrm{~min}$, which allows the large temporal and spatial variability of embedded convection to be captured. The simulation is initialized at 00:00 UTC on 7 October 2016 and runs for $106 \mathrm{~h}$ with initial and lateral boundary conditions from the ECMWF analyses with a horizontal resolution of $0.1^{\circ}$ every $6 \mathrm{~h}$.

The detailed WCB ascent behavior is analyzed with online trajectories computed during the COSMO simulation (Miltenberger et al., 2013, 2014), which are used to identify phases of embedded convective ascent in the WCB ascent region (Rasp et al., 2016; Oertel et al., 2019, 2020). The online trajectories are started every $2 \mathrm{~h}$ during the first $96 \mathrm{~h}$ of the simulation from a predefined starting region (which is determined based on the offline WCB trajectory positions) at seven vertical levels $(250,500,750,1000,1500,2000$ and 2500 m a.s.1.). 
The local strength of WCB trajectory ascent is quantified through the centered $2 \mathrm{~h}$ net pressure change $\Delta p_{2 \mathrm{~h}}(t)=$ $p(t+1 \mathrm{~h})-p(t-1 \mathrm{~h})$ along the online WCB trajectories, which is calculated for all trajectories that exceed an ascent rate of $600 \mathrm{hPa}$ in $48 \mathrm{~h}$. WCB ascent phases have previously been considered as convective if $\Delta p_{2} \mathrm{~h}<-320 \mathrm{hPa}(2 \mathrm{~h})^{-1}$ (Rasp et al., 2016; Oertel et al., 2019). More extreme values of $\Delta p_{2 \mathrm{~h}}<-600 \mathrm{hPa}(2 \mathrm{~h})^{-1}$ can, however, also be embedded in the WCB ascent region (Rasp et al., 2016; Oertel et al., 2019, 2020).

\section{Evolution of the WCB and its embedded convection}

\subsection{Synoptic situation}

The surface cyclone that was later associated with the upperlevel PV cutoff Sanchez has formed several days before the research flights on 9 and 10 October 2016. The genesis region south of $40^{\circ} \mathrm{N}$ is situated in a warm and moist environment where the equivalent potential temperature $\left(\theta_{\mathrm{e}}\right)$ at $850 \mathrm{hPa}$ exceeds $335 \mathrm{~K}$ and is located south of the stronger, relatively zonal polar jet with $60 \mathrm{~m} \mathrm{~s}^{-1}$ at $60^{\circ} \mathrm{N}$. In the early phase, the surface cyclone remains quasi-stationary below an upper-level PV anomaly and west of a surface anticyclone and only travels slowly eastward and northward across the North Atlantic (Oertel, 2019, Fig. 5.2).

Eventually, on 8 October the surface cyclone propagates poleward influenced by the steering flow of the anticyclone located to its east and the upper-level trough that approaches the cyclone from the northwest (Fig. 1a, d). During the poleward propagation the surface cyclone intensifies and the cold and warm fronts strengthen in hand with the intensification of the cyclone (Fig. 1b, c). A first PV streamer breakup occurs early on 9 October (see Schäfler et al., 2018), but the stratospheric PV cutoff does not interact with the surface cyclone and propagates equatorward. The key interaction between the surface cyclone and an upper-level PV cutoff, which is clearly visible at $320 \mathrm{~K}$, occurs later on 9 October at $45^{\circ} \mathrm{N}$ during the second PV streamer roll-up and cutoff formation. Then, the PV cutoff and the surface cyclone lock phases, leading to rapid intensification of the surface cyclone (Fig. 1b, c). During this intensification the surface pressure drops by $15 \mathrm{hPa}$ within $15 \mathrm{~h}$ to a minimum of $985 \mathrm{hPa}$. The surface cyclone and the upper-level PV cutoff align barotropically (Fig. 1b, c) and propagate eastward towards southern Europe (not shown), where the PV cutoff and associated WCB lead to high-impact weather across southern France, including heavy precipitation, flooding and strong winds (Schäfler et al., 2018; Binder et al., 2020). Schäfler et al. (2018) and Oertel (2019, Chapter 5) provide a more detailed description of the synoptic situation and the evolution of the surface cyclone and associated upper-level PV cutoff. During this period (8-11 October) the forecast quality in the North Atlantic region was relatively low with a com- paratively large root mean square error and ensemble spread of $500 \mathrm{hPa}$ geopotential (Schindler et al., 2020). Uncertainty in the PV cutoff position was associated with a misrepresentation of the heavy precipitation event that occurred downstream over southern France (Binder et al., 2020).

\subsection{WCB ascent and cloud structure}

During its life cycle, the cyclone is associated with a prominent WCB (Fig. 1g-i). After the interaction with the upperlevel trough and developing PV streamer at approximately $45^{\circ} \mathrm{N}$, the WCB trajectories ascend poleward and form a pronounced anticyclonic branch that reaches $60^{\circ} \mathrm{N}$ (Fig. 1g, h). The WCB ascends primarily in two regions, in a narrow band ahead of the surface cold front and above the warm frontal surface, and forms a pronounced cloud band with cloud tops exceeding $200 \mathrm{hPa}$ (Fig. 1d-f). The large-scale cloud band strongly associated with warm frontal WCB ascent covers large parts of the upper-level ridge (Fig. 1d, e) and wraps cyclonically around the cyclone center during the PV cutoff formation (Fig. 1e). Both cold and warm frontal cloud bands are characterized by high clouds with heterogeneously structured cloud tops (Fig. 1d-f). In particular, the cold frontal clouds form a narrow vertically extended band with cloud tops exceeding $150-200 \mathrm{hPa}$ (Fig. 1e, f). South of $40^{\circ} \mathrm{N}$, deep clouds with very high cloud tops coincide with lightning observations from the World Wide Lightning Location Network (WWLLN; Abarca et al., 2010) indicating that deep convective clouds are embedded in the extended WCB cloud band (Fig. 1a, b). This convective character of the cloud band is particularly pronounced in the early phase of the WCB (e.g., Fig. 1d).

\subsection{Evolution of embedded convection}

The position of the upper-level trough (cf. Fig. 1a, j), its thinning and the PV streamer development (cf. Fig. 1b, k) as well as the PV cutoff formation are well captured by the COSMO simulation (cf. Fig. 1c, 1). Moreover, the WCB ascent region of the COSMO simulation (Fig. 1j-1) agrees with the WCB ascent region of the ECMWF WCB trajectories (Fig. 1g-i) and coincides with the large-scale cloud band (Fig. 1d-f).

To investigate the WCB ascent behavior, the $2 \mathrm{~h}$ ascent rates $\Delta p_{2} \mathrm{~h}$ along online trajectories are shown in Fig. $1 \mathrm{j}-1$. Slantwise and stratiform cloud-forming WCB ascent is typically characterized by moderate $\Delta p_{2} \mathrm{~h}$ values of approximately -50 to $-300 \mathrm{hPa}$, while embedded convective ascent phases reach $\Delta p_{2} \mathrm{~h}$ values of -320 to $-400 \mathrm{hPa}$ and can even exceed $-600 \mathrm{hPa}$ (Rasp et al., 2016; Oertel et al., 2019). For cyclone Sanchez, such convective ascent phases are frequently embedded within the overall slantwise WCB ascent region (Fig. 1j-1). In agreement with the cloud structure and lightning observations (Fig. 1d), the most intense embedded convection $\left(\Delta p_{2} \mathrm{~h}<-600 \mathrm{hPa}\right.$ ) occurs frequently in the early phase before the PV cutoff formation near the 

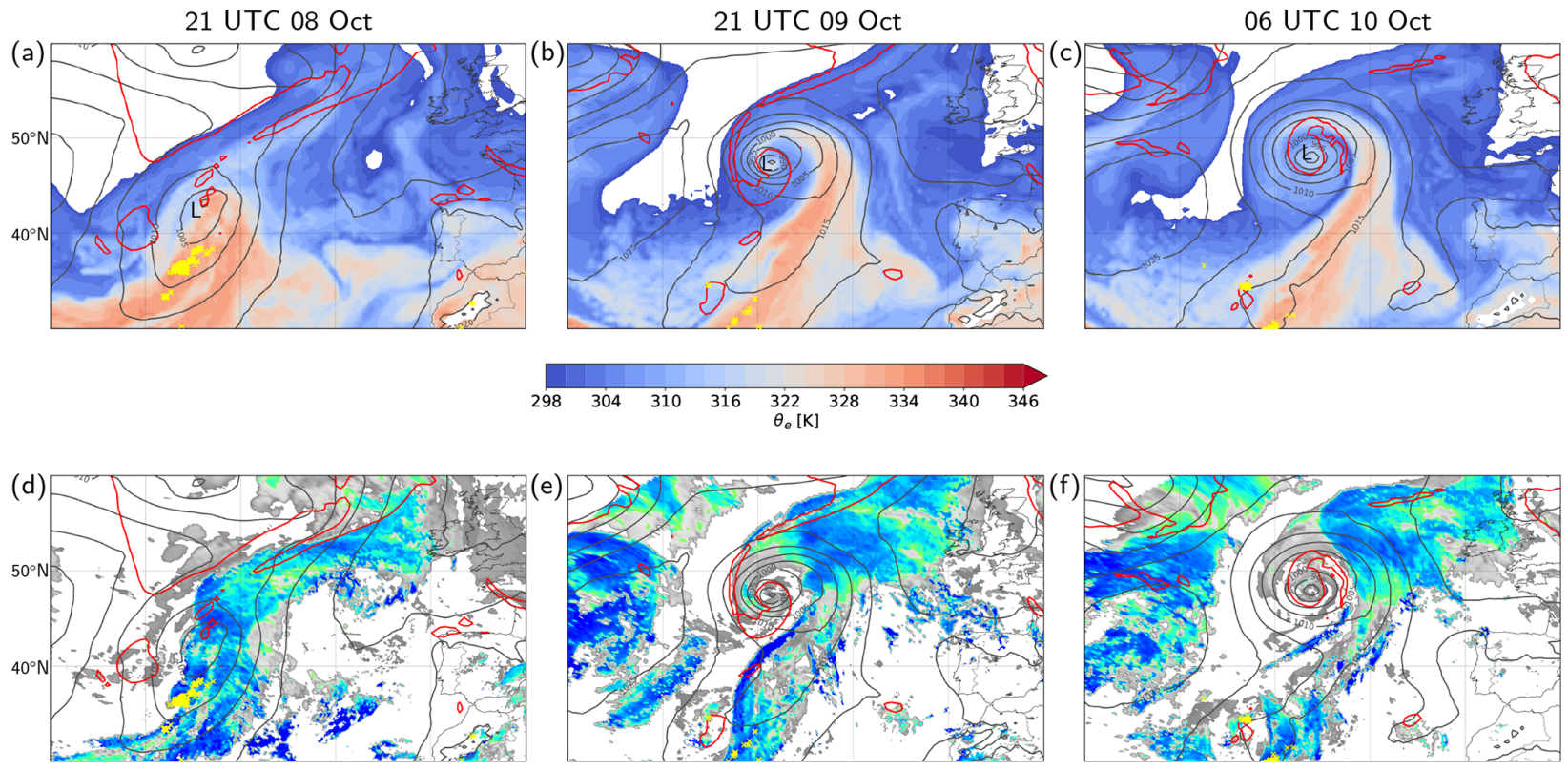

$\begin{array}{rl}700 \quad 650 \quad 600 & 550500450 \quad 400 \quad 350 \quad 300 \quad 250 \quad 200 \\ \text { cloud top pressure }[\mathrm{hPa}]\end{array}$
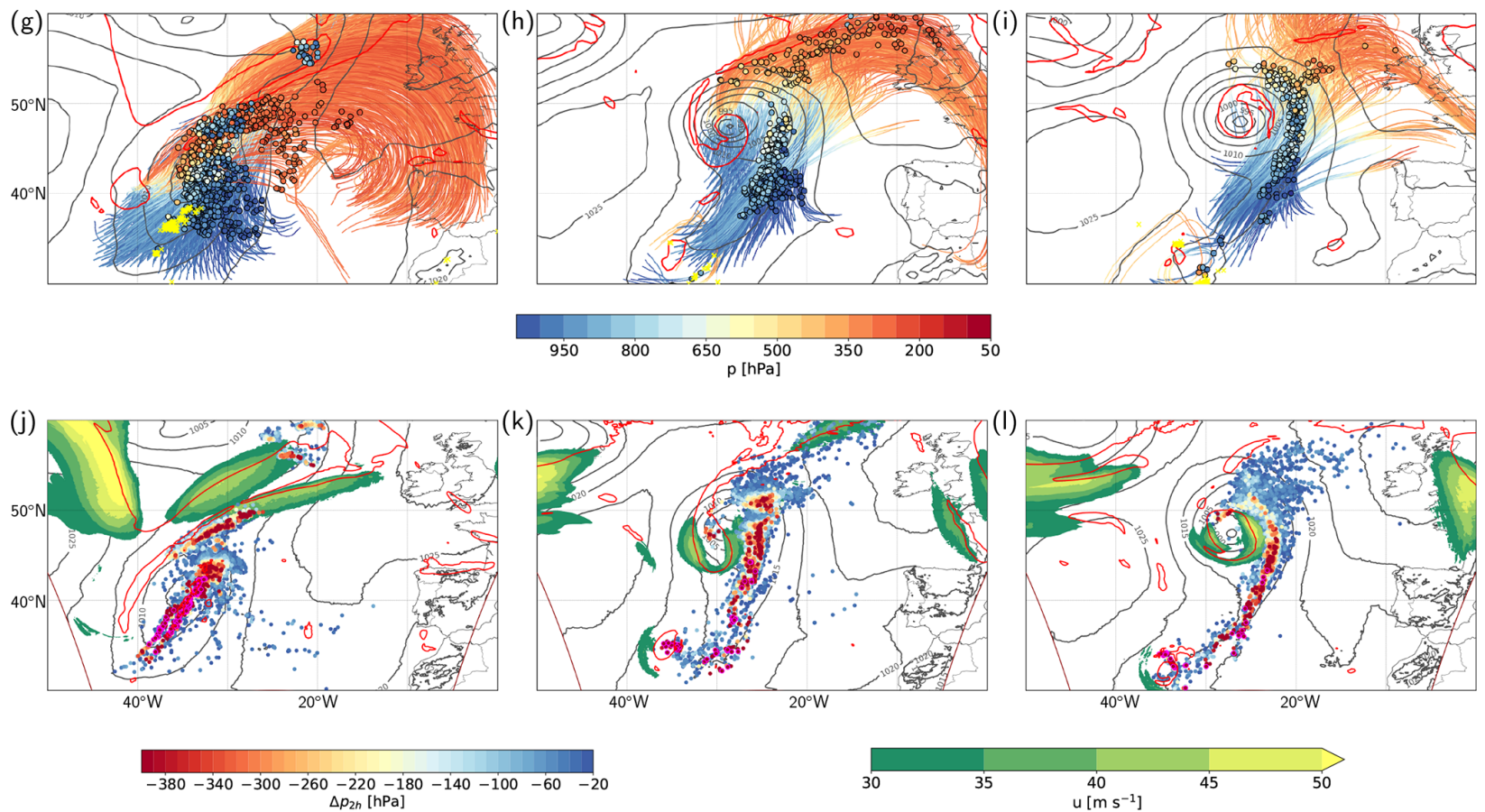

Figure 1. Overview of the surface cyclone and PV cutoff Sanchez: (a-c) sea level pressure (SLP, grey contours, every 5 hPa), 2 PVU at $320 \mathrm{~K}$ (red) and equivalent potential temperature $\left(\theta_{\mathrm{e}}\right)$ at $850 \mathrm{hPa}$ (colors, in $\mathrm{K}$ ) from the ECMWF dataset, and lightning observations (yellow) at (from left to right) 21:00 UTC on 8 October 2016, 21:00 UTC on 9 October 2016 and 06:00 UTC on 10 October 2016; (d-f) as (a-c) but for satellite-derived cloud top pressure (colors, in hPa), with data from Meteosat Second Generation Satellites (EUMETSAT; Schmetz et al., 2002); (g-i) as (a-c) but for WCB trajectories (colored according to pressure) from the ECMWF dataset started $18 \mathrm{~h}$ before the times shown in $(\mathbf{a}-\mathbf{c})$ and WCB trajectory positions (circles colored according to pressure) for the times shown in $(\mathbf{a}-\mathbf{c})$; $(\mathbf{j}-\mathbf{l})$ centered $2 \mathrm{~h}$ pressure change ( $\Delta p_{2} \mathrm{~h}$, colored circles, in $\mathrm{hPa}$ ) along ascending WCB trajectories from the convection-resolving COSMO simulation, $2 \mathrm{PVU}$ (red) contour and jet (colors, in $\mathrm{m} \mathrm{s}^{-1}$ ) at $320 \mathrm{~K}$, and SLP (grey contours, every $5 \mathrm{hPa}$ ) from the COSMO simulation for the same times as shown above. 
cyclone center and at the cold front (Fig. 1j, magenta outline). After the northward propagation of the cyclone, these intense convective ascent phases with $\Delta p_{2 \mathrm{~h}}<-600 \mathrm{hPa}$ become scarcer, but $\Delta p_{2} \mathrm{~h}$ values still remain below $-400 \mathrm{hPa}$ (Fig. 1k, 1).

During the PV streamer roll-up and cutoff formation and simultaneous deepening of the surface cyclone, the ascending WCB air parcels aggregate mainly in two banded regions, ahead of the cold front and at the warm front, with $\Delta p_{2} \mathrm{~h}$ values that vary between $-25 \mathrm{hPa}$ and -400 to $-600 \mathrm{hPa}$ at the cold front (Fig. 1k, 1). Convective ascent with $\Delta p_{2 \mathrm{~h}}<$ $-320 \mathrm{hPa}$ occurs ahead of the surface cold front and near the warm front northeast of the cyclone center and is directly embedded in the region of slower slantwise WCB ascent. Although convective ascent phases with $\Delta p_{2} \mathrm{~h}<-320 \mathrm{hPa}$ are embedded in the $\mathrm{WCB}$ ascent region at both the cold and warm front, the warm-frontal convective WCB ascent is generally more moderate with $\Delta p_{2} \mathrm{~h}$ values of up to only $-350 \mathrm{hPa}$, in contrast to the intense cold frontal convection with $\Delta p_{2} \mathrm{~h}$ values in the range of -400 to $-600 \mathrm{hPa}$.

In summary, convective activity identified from COSMO online trajectories is frequently embedded in the WCB of cyclone Sanchez at the cold and warm fronts. The embedded convective ascent phases show substantial variability in intensity, whereby the most intense convective ascent occurs near the cyclone center and ahead of the cold front primarily in the early phase and south of $45^{\circ} \mathrm{N}$. This allows for an investigation of the effect of intense vs. moderate embedded convection on surface precipitation and upper-level PV modification. This will follow in Sect. 5, after a detailed analysis of airborne radar observations in the next section.

\section{Radar reflectivity structure of the WCB}

During the research flights on 9 and 10 October, the HALO aircraft observed the WCB cloud band several times. The different flight legs captured different stages of the WCB, including slantwise and stratiform cloud-forming regions as well as two convective regions with $\Delta p_{2} \mathrm{~h}$ values ranging from $-25 \mathrm{hPa}$ in the stratiform regions to $-400 \mathrm{hPa}$ in the convective regions near the flight track (Figs. 2a and 3a). As the southernmost flight legs of HALO were located at around $47^{\circ} \mathrm{N}$, the most intense convective regions with $\Delta p_{2} \mathrm{~h}$ $<-600 \mathrm{hPa}$ (Sect. 3.3 and Fig. 1j) were not captured. The differing WCB ascent behavior seen in $\Delta p_{2} \mathrm{~h}$ values is also reflected in the radar observations. In the following, three contrasting radar reflectivity cross sections of the extended WCB cloud band are discussed, whereby the large-scale WCB ascent region is identified through offline trajectories from the ECMWF analyses.

The first observation of the WCB cloud band on 9 October took place from 13:00 to 14:00 UTC at around $48^{\circ} \mathrm{N}$ (Fig. 2a). At 13:00 UTC the HALO crossed the PV streamer from west to east and subsequently entered the warm sec- tor across the warm front near the cyclone center (Fig. 2a). Before turning back and traversing the PV streamer a second time from east to west, thereby crossing the front, HALO observed the WCB cloud band between 13:20 and 14:00 UTC (Fig. 2a, yellow line). For the second observation of the WCB cloud band on 9 October, HALO traversed the large-scale cloud band from west to east at 16:00 UTC north of $50^{\circ} \mathrm{N}$ (Fig. 2a, violet line).

Stratiform cloud band related to slantwise WCB ascent. The observation of the WCB cloud band in the northern part of the WCB outflow at 16:00 UTC emphasizes its predominantly stratiform character (Fig. 2b), which coincides with a region of comparatively slowly ascending WCB trajectories with $\Delta p_{2} \mathrm{~h}$ in the range from -25 to $-50 \mathrm{hPa}$ (Fig. 2a, violet line and b, grey shading). The large-scale cloud band, extending to about $9 \mathrm{~km}$ height, is characterized by a relatively homogeneous radar reflectivity, a closed upper-level cloud top and a well-defined bright band at $2 \mathrm{~km}$ height. This extended cloud band is associated with WCB ascent in the mid-troposphere to upper troposphere between 4 and $9 \mathrm{~km}$ height. The mostly stratiform character of this cloud band is confirmed by the IFS dataset, which produces hardly any convective precipitation along the flight track (Fig. 2b, bottom panel), but moderate large-scale precipitation of up to $2.5 \mathrm{~mm} \mathrm{~h}^{-1}$ (not shown).

Convective plumes associated with WCB ascent. The WCB cloud band further south at $48^{\circ} \mathrm{N}$ near the cyclone center (Fig. 2c) differs substantially from the stratiform cloud structure observed in the northern part of the WCB cloud band (Fig. 2b). The radar reflectivity $Z$ in this region is very heterogeneous with spatially confined narrow convective plumes that extend from the boundary layer to $6-8 \mathrm{~km}$ height and locally exceed the cloud top height in their direct surroundings, which accentuates the convective character (Fig. 2c). Due to these vertically extended narrow convective towers, the cloud top is heterogeneous and cloud top height locally varies between $5-8 \mathrm{~km}$. The radar reflectivity $Z$ within the convective plumes amounts to approximately $25 \mathrm{dBZ}$, with values ranging from $20-25 \mathrm{dBZ}$ even in the upper troposphere several kilometers above the melting layer. Hence, although $Z$ does not exceed $25 \mathrm{dBZ}$, the embedded convective updrafts can be clearly identified as individual narrow plumes, which directly coincide with WCB air masses between 1 and $6 \mathrm{~km}$ height. This qualitatively confirms results from previous studies (Crespo and Posselt, 2016; Oertel et al., 2019; Blanchard et al., 2020), although absolute values of radar reflectivity are difficult to compare since in strongly precipitating regions attenuation effects through Mie scattering have to be considered at shorter wavelengths (e.g., Ewald et al., 2019). This affects systems like the $94 \mathrm{GHz}$ CloudSat radar (analyzed by Crespo and Posselt, 2016) and the $95 \mathrm{GHz}$ RASTA radar (analyzed by Blanchard et al., 2020) more strongly than the MIRA-36 used here, which uses a slightly larger wavelength. 
Near the observed convective plumes, COSMO WCB trajectories frequently perform a convective ascent with $\Delta p_{2 \mathrm{~h}}<-400 \mathrm{hPa}$ (Fig. 2a, yellow line and c, grey shading). These phases of convective WCB ascent aggregate northeast of the cyclone center and are directly embedded in a region of slantwise WCB ascent with $\Delta p_{2} \mathrm{~h}$ values between -50 and $-150 \mathrm{hPa}$. Near the flight track, additional regions of convective WCB ascent with $\Delta p_{2} \mathrm{~h}<-320 \mathrm{hPa}$ occur near the warm and cold fronts. The convective character of the WCB cloud band is corroborated by the production of substantial convective precipitation by the IFS parameterization scheme (Fig. 2c, bottom panel). The comparison between the observations from both flight legs emphasizes the diverse cloud structure associated with the WCB that can range from a homogeneous, large-scale, closed-top cloud band (Fig. 2b) to a heterogeneously structured cloud with embedded convective plumes and a broken cloud top (Fig. 2c).

Weaker convection embedded in extended WCB cloud band. The flight on 10 October sampled the WCB ascent and outflow region twice during two subsequent west-east traverses (Fig. 3a, yellow line) and provides another example of embedded convection in the WCB ascent region (Fig. 3b). Near the flight track, WCB air parcels ascend with $\Delta p_{2} \mathrm{~h}$ values between -250 and $-320 \mathrm{hPa}$ with few WCB air parcels with $\Delta p_{2 \mathrm{~h}}$ below $-320 \mathrm{hPa}$ (Fig. 3a and b, grey shading). These ascent rates are faster than a purely slantwise ascending WCB trajectory $\left(\Delta p_{2 \mathrm{~h}} \approx-50 \mathrm{hPa}\right.$; Fig. $\left.2 \mathrm{~b}\right)$, but the convective WCB ascent phases are slightly slower and less frequent than the extended region of convective WCB ascent near the cyclone center on 9 October (Fig. 2c). In the radar observations the convective plumes at around 14:30 and 15:15 UTC, which also approximately coincide with parameterized convective precipitation and small $\Delta p_{2} \mathrm{~h}$ values, are less well defined and stand out less (Fig. 3b) compared to the extended region with embedded convection near the cyclone center (Fig. 2c). Moreover, the regions of faster WCB ascent, characterized by narrow locally confined regions of enhanced radar reflectivity, are directly embedded in the larger-scale vertically elevated cloud band with stratiform characteristics, such as regions of homogeneous radar reflectivity and a bright band which is visible in most regions. Nevertheless, the large-scale WCB cloud band is more heterogeneous than the stratiform cloud band in the northern part of the WCB (Fig. 2b) and includes confined plumes of locally increased radar reflectivity that extend up to $6-8 \mathrm{~km}$ height, which indicates the occurrence of locally faster WCB ascent associated with embedded convective activity.

The comparison of the radar reflectivity cross sections from the first (Fig. 2b, c) and the second flight (Fig. 3b) illustrates the large spatial and temporal heterogeneity of the WCB cloud band. On the one hand, the extended and dense WCB cloud band has a stratiform character associated with primarily slantwise WCB ascent. On the other hand, it includes embedded convection in the WCB ascent region very close to the cyclone center, at a distance of about $300 \mathrm{~km}$ from the stratiform region. Moreover, the various degrees of heterogeneity of the radar reflectivity structure - which reflect the strength of embedded ascent phases - illustrate the almost continuous transformation from the slantwise to the convective WCB ascent regime (see Oertel et al., 2019). Hence, the radar observations emphasize the diverse representation and manifold character of the WCB cloud band including its embedded convection, thereby corroborating its heterogeneity.

The comparison between the airborne radar observations and the online trajectories from the convection-permitting simulation shows that qualitatively the COSMO online trajectories cannot only successfully identify regions of embedded convection in the WCB ascent region but can also differentiate between different degrees of the strength of embedded convection. In summary, regions with stronger convective updrafts include well-defined individual plumes of increased $Z$ and are characterized by large spatial heterogeneity of $Z$. These regions also coincide with abundant convective WCB ascent in the COSMO simulation with $\Delta p_{2} \mathrm{~h}<$ $-400 \mathrm{hPa}$. Weaker embedded convection, however, stands out less against the large-scale stratiform cloud band but can nevertheless be identified by enhanced heterogeneity and less coherent, vertically extended regions of increased $Z$. In the COSMO simulations, this weaker embedded convection can be identified through intermediate $\Delta p_{2} \mathrm{~h}$ values, which are substantially larger than for a pure slantwise ascent, but still slower than the stronger convective updrafts observed near the cyclone center. In the following, we extend the analysis of embedded convection beyond the region where HALO observed the WCB cloud band; i.e., we also include very intense convection in the early phase of the cyclone with $\Delta p_{2 \mathrm{~h}}<-600 \mathrm{hPa}$ (Fig. 1j).

\section{Characteristics of intense vs. moderate WCB-embedded convection}

Radar observations and online WCB trajectories showed the frequent occurrence of convection with differing ascent speeds embedded in the WCB of cyclone Sanchez. In the following, we systematically compare characteristics of intense vs. moderate WCB-embedded convection in the COSMO simulation. In addition to $\Delta p_{2} \mathrm{~h}$, we now use two alternative measures to describe the WCB trajectory ascent speed in the entire cyclone, which allow for a more detailed distinction of the intensity of convection and are particularly useful for comparison of ascent speed with other studies (e.g., Carbone, 1982; Flaounas et al., 2016; Oertel et al., 2019; Oertel, 2019; Blanchard et al., 2020). These are the minimum times required for an ascent of 400 and $600 \mathrm{hPa}\left(\tau_{400}\right.$ and $\left.\tau_{600}\right)$, respectively, and ascent speed $\left(\omega\right.$, in $\mathrm{Pas}^{-1}$ and $w$, in $\left.\mathrm{ms}^{-1}\right)$ averaged over these 400 and $600 \mathrm{hPa}$ segments. $\tau_{400}$ and $\tau_{600}$ values demonstrate the large variability of ascent rates for the 

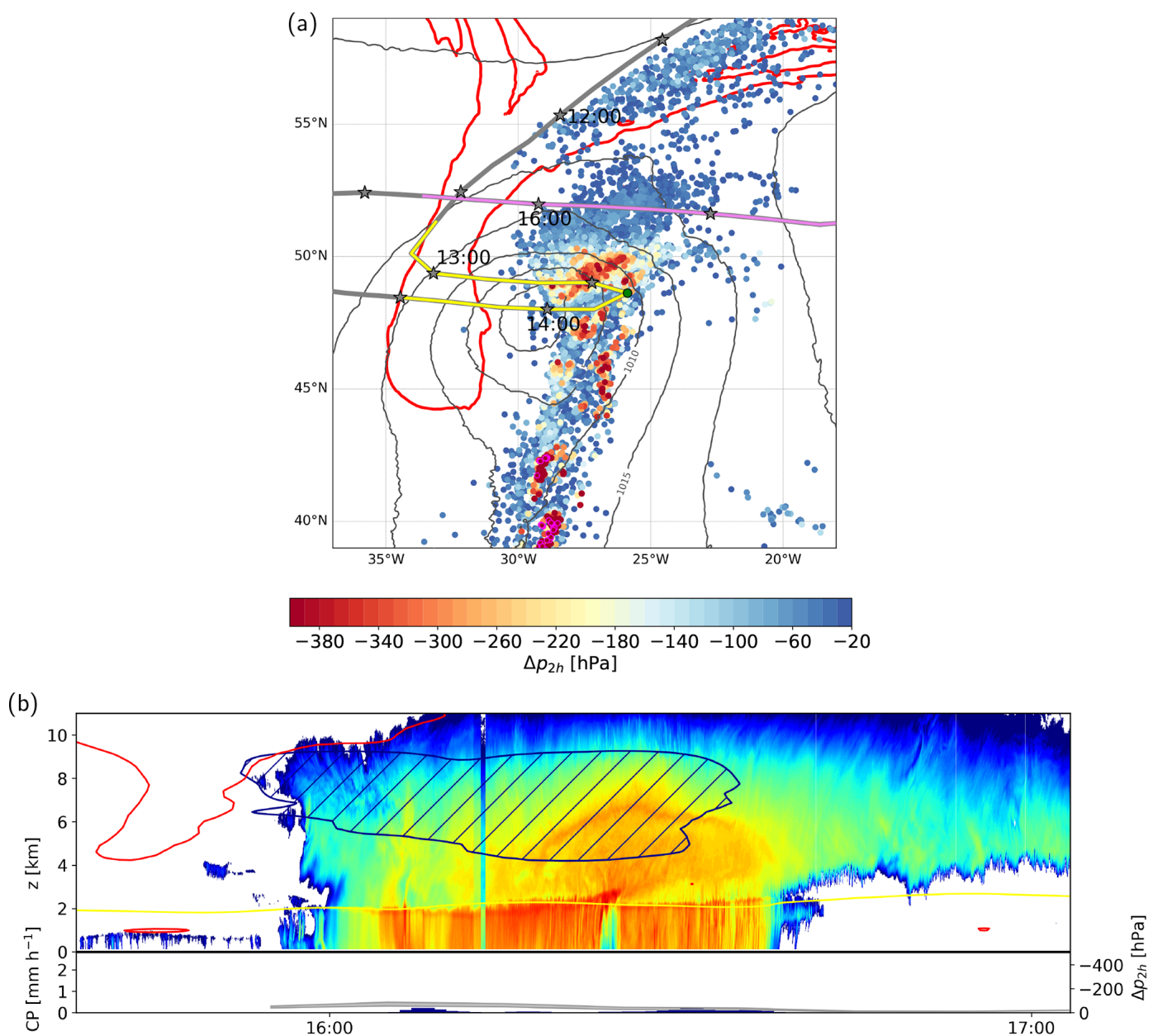

(c)

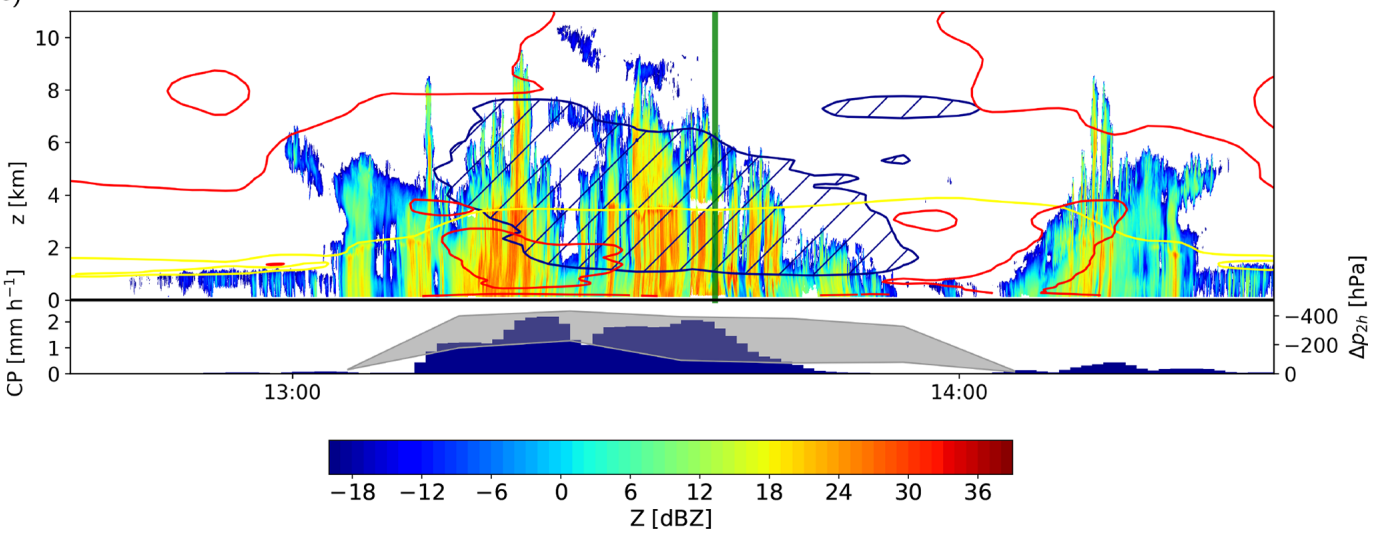

Figure 2. (a) HALO flight track (grey) on 9 October 2016 including $2 \mathrm{~h}$ pressure changes ( $\Delta p_{2} \mathrm{~h}$, colored points) of COSMO WCB trajectories centered at 13:30 UTC, SLP (grey contours, every $5 \mathrm{hPa}$ ) and $2 \mathrm{PVU}$ at $320 \mathrm{~K}$ (red). COSMO WCB air parcels ascending more than $600 \mathrm{hPa}$ in $2 \mathrm{~h}$ are shown by magenta encircled dots. The grey asterisks indicate the position of the aircraft every 30 min. Violet and yellow parts of the flight track denote the cross sections shown in (b, c) from 15:40 to 17:00 UTC and from 12:40 to 14:30 UTC, respectively. (b, c) Radar reflectivity factor $Z$ (in dBZ) along (b) the violet segment and (c) the yellow segment in (a) including WCB mask from ECMWF WCB trajectories (dark blue contour and hatching), the $0^{\circ} \mathrm{C}$ isotherm (yellow) and the $2 \mathrm{PVU}$ contour (red). The bottom panels show ECMWF convective precipitation $\left(\mathrm{CP}\right.$, in $\mathrm{mm} \mathrm{h}^{-1}$ ) along the flight track (blue bars) and range of $25 \%$ fastest $2 \mathrm{~h}$ ascent phases of COSMO WCB air parcels (i.e., $25 \%$ smallest $\Delta p_{2} \mathrm{~h}$ values) shown in (a) within a radius of $75 \mathrm{~km}$ around the aircraft position (in hPa, grey shading). The green line in (c) at 13:40 UTC marks the aircraft turning point east of the cyclone center and is marked as green dot in (a). 
(a)
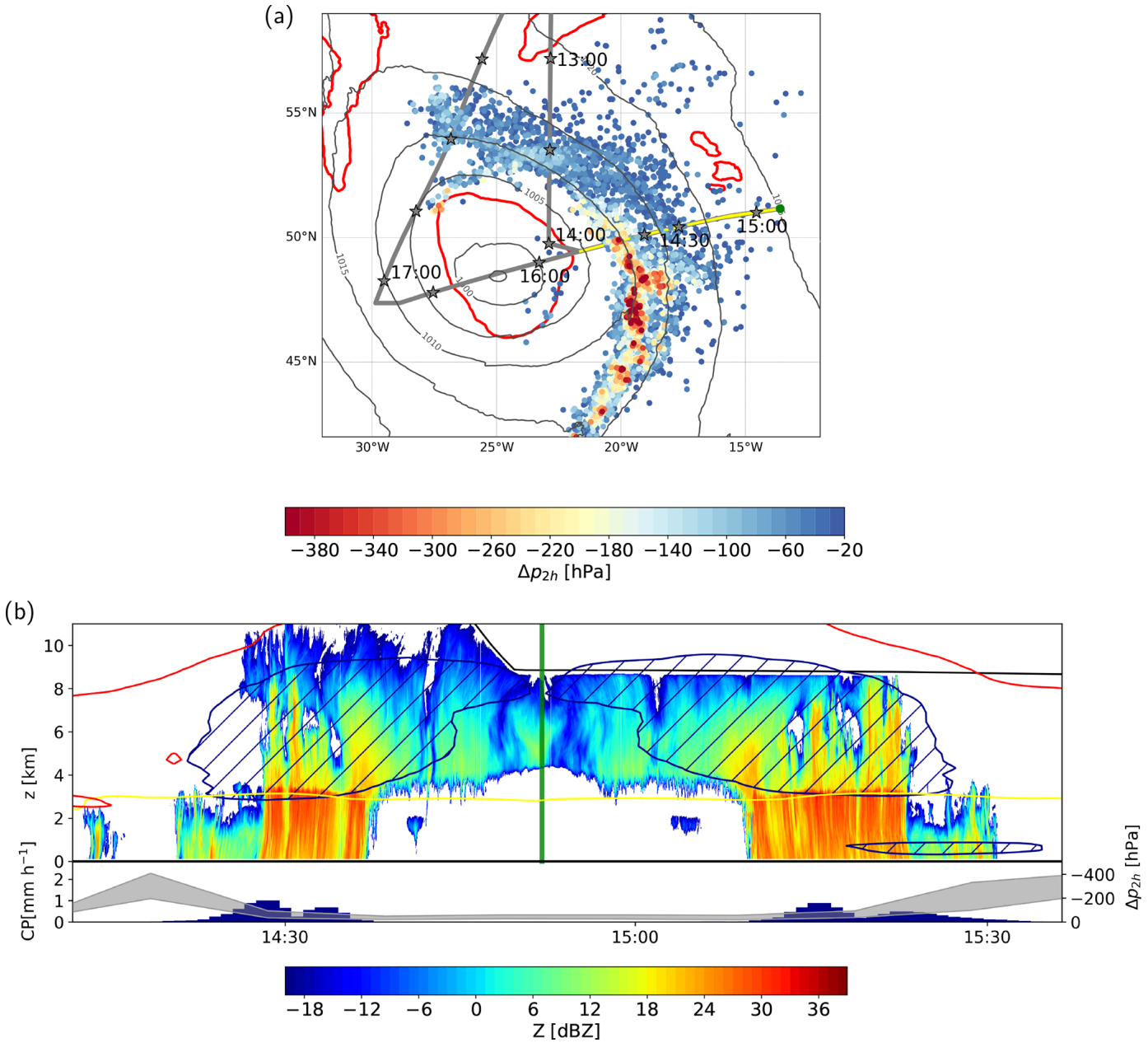

Figure 3. (a) As Fig. 2a but on 10 October 2016 with COSMO online trajectories centered at 15:00 UTC. The cross section shown in (b) is marked in yellow (14:10-15:40 UTC). (b) As Fig. 2b but on 10 October from 14:10-15:40 UTC. Also shown is the aircraft height (black). The green line at 14:50 UTC marks the eastern aircraft turning point and is marked as green dot in (a).

WCB and its embedded convection ranging from below $1 \mathrm{~h}$ to more than $24 \mathrm{~h}$ (Fig. 4). The frequency distributions for $\tau_{400}$ (Fig. 4a) and $\tau_{600}$ (Fig. 4b) are bimodal with a first local maximum at short durations of about $30 \mathrm{~min}$ and $1 \mathrm{~h}$, respectively, and a second maximum at 2.5 and $6 \mathrm{~h}$, respectively. Interestingly, the second maximum of $\tau_{400}$ of $2.5 \mathrm{~h}$ corresponds to a previously used threshold for embedded convection (Rasp et al., 2016; Oertel et al., 2019) separating the slantwise from the convective WCB ascent regime. The $10 \%$ lowest $\tau_{400}$ and $\tau_{600}$ values for all WCB trajectories are below $20 \mathrm{~min}$ and $1 \mathrm{~h}$, respectively. This left tail of the distribution shows that embedded convective WCB ascents with averaged $\omega$ of approximately $17-33 \mathrm{~Pa} \mathrm{~s}^{-1}$ (corresponding to $\tau_{400}=20 \mathrm{~min}$ and $\tau_{600}=1 \mathrm{~h}$ ) occur quite often in this cyclone. In terms of $w$, the ascent velocity of embedded convection amounts to approximately $3-5 \mathrm{~m} \mathrm{~s}^{-1}$. This is about 2 orders of magnitude faster than a hypothetical purely slantwise ascending WCB trajectory with $w=0.06 \mathrm{~m} \mathrm{~s}^{-1}\left(\omega=0.3 \mathrm{~Pa} \mathrm{~s}^{-1}\right.$; assuming a continuous $48 \mathrm{~h}$ ascent of $600 \mathrm{hPa}$ or approximately
$10 \mathrm{~km})$ and also exceeds the previously reported ascent velocities of WCB-embedded convection (ranging between 1$17 \mathrm{~Pa} \mathrm{~s}^{-1}$, e.g., Flaounas et al., 2016; Rasp et al., 2016; Oertel et al., 2019, 2020; Blanchard et al., 2020). The ascent velocities indicate that faster and even more intense convection with ascent velocities that are similar to deep convective ascent at squall lines (Rasp et al., 2016) - can also be embedded in WCBs.

\subsection{Lagrangian composite analysis}

In the following, we perform a 3D Lagrangian composite analysis following the method of Oertel et al. (2020) to compare the characteristics and signatures of relatively moderate and intense convection embedded in the WCB of cyclone Sanchez (Fig. 5). During the evolution of the surface cyclone, both the upper-level flow structure changes and the strength of convective WCB ascent differs (see Sect. 3.3). In particular, embedded convection in the early phase (Fig. 1j) is 

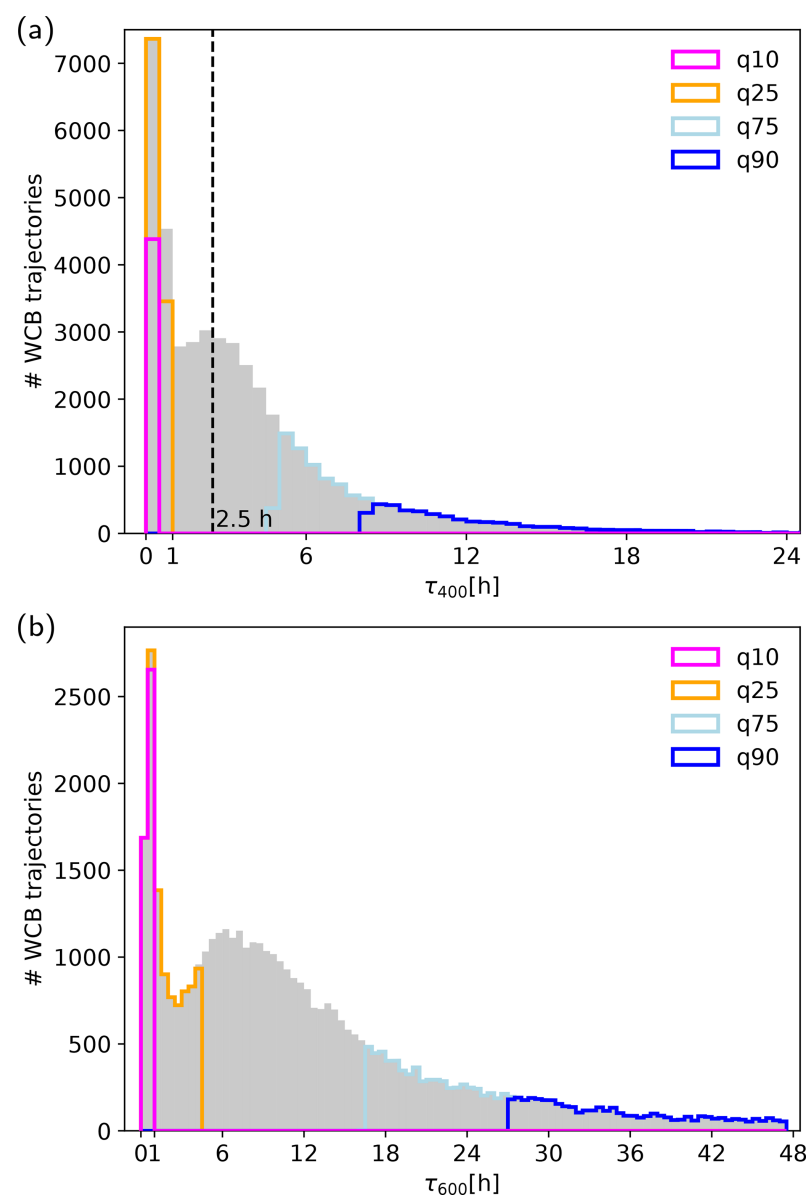

Figure 4. Histogram of the duration of the fastest (a) $400 \mathrm{hPa}$ ascent phases $\left(\tau_{400}\right)$ and (b) $600 \mathrm{hPa}$ ascent phases $\left(\tau_{600}\right)$ embedded in all WCB trajectories of cyclone Sanchez. The 10th, 25th, 75th and 90th percentiles are colored in magenta, orange, light blue and blue, respectively. The dashed line at $\tau_{400}=2.5 \mathrm{~h}$ in (a) indicates a previously used threshold for WCB-embedded convection (Rasp et al., 2016; Oertel et al., 2019). Note the different axes' dimensions in (a) and (b).

much more intense than in the later phase (Fig. 1k,l). However, the compositing technique requires a coherent trajectory ascent from the lower to the upper troposphere and a similar synoptic-scale flow situation to not smear out the signals. Hence, we compare two sub-categories of convective WCB trajectories that ascend coherently in two sub-regions of the WCB: (i) very rapidly ascending, intense convective WCB trajectories, and (ii) moderately ascending (but still) convective WCB trajectories (Fig. 5). In the following, the selection criteria for both convective WCB sub-categories are described in more detail.

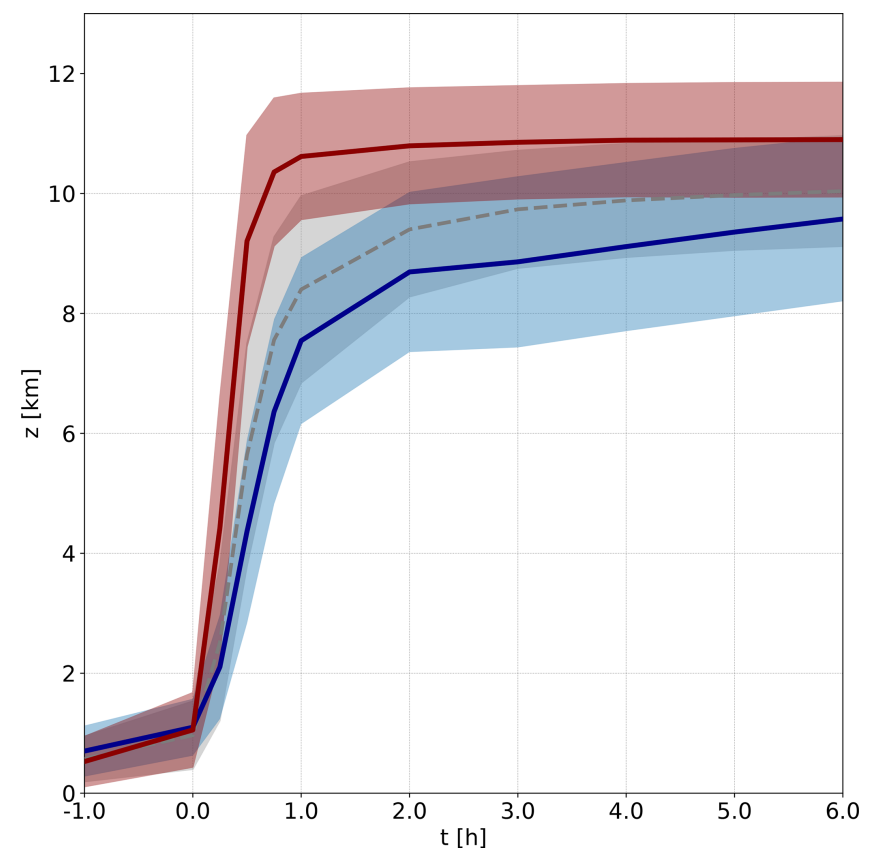

Figure 5. Mean ascent (solid lines; shading shows mean \pm standard deviation) of selected moderate convective (blue) and intense convective (red) WCB trajectories of cyclone Sanchez that are used for the composite analysis. For comparison, the ascent of embedded convective WCB trajectories of cyclone Vladiana investigated by Oertel et al. (2020) is also shown (grey).

\subsection{Trajectory selection and ascent region}

Intense convective WCB trajectories. The selected intense convective WCB trajectories ascend through the entire troposphere in less than $1 \mathrm{~h}$ (Fig. 5). On average, these trajectories ascend from 1 to $9 \mathrm{~km}$ height in only $30 \mathrm{~min}$ and reach their final outflow level at $11 \mathrm{~km}$ height within $1 \mathrm{~h}$. Their $\tau_{400}$ and $\tau_{600}$ values amount to $20 \mathrm{~min}$ and $1 \mathrm{~h}$, respectively (corresponding to the 10th percentile of all $\tau_{400}$ and $\tau_{600} \mathrm{val}-$ ues for cyclone Sanchez). This translates to averaged 400 and $600 \mathrm{hPa}$ ascent velocities of 33 and $17 \mathrm{~Pa} \mathrm{~s}^{-1}$, respectively, i.e., this sub-category represents intense deep convection with clearly faster ascent velocities compared to WCBembedded convection of cyclone Vladiana, which occurred 2 weeks earlier in September 2016 (Oertel et al., 2020). In particular, the sub-category also includes convective WCB trajectories with the shortest $\tau_{600}$ of only $30 \mathrm{~min}$, i.e., the WCB trajectories traverse the entire $600 \mathrm{hPa}$ layer from the boundary layer into the upper troposphere with an average ascent rate of $33 \mathrm{~Pa} \mathrm{~s}^{-1}\left(6 \mathrm{~m} \mathrm{~s}^{-1}\right)$. Approximately 2000 trajectories fall in the category of intense convective WCB trajectories. The intense convective WCB trajectories ascend from 7-9 October predominantly between $35-40^{\circ} \mathrm{N}$ (on average at $38^{\circ} \pm 2.0^{\circ}$; Fig. $6 \mathrm{a}$, black outlined circles) at a substantial distance from the upper-level jet, as during this early stage of the cyclone, the WCB-embedded intense convection 
occurs further south and also closer to the cyclone center (Fig. 1j).

Moderate convective WCB trajectories. The trajectories in the moderate convective WCB sub-category are spatially and temporally separated from the intense convective WCB trajectories (Fig. 6a). They ascend north of $40^{\circ} \mathrm{N}$ (on average at $43^{\circ} \pm 1.8^{\circ}$ ) between 12:00 UTC on 9 October and 12:00 UTC on 11 October during the PV cutoff phase (Fig. 6a, white outlined triangles). During this time period convective WCB ascent is overall slower than in the early phase of the cyclone (Fig. 1j-1). Hence, the moderate convective WCB trajectories are characterized by a slower ascent (Fig. 5), whereby the trajectories perform an initial convective $400 \mathrm{hPa}$ deep ascent from $1 \mathrm{~km}$ to approximately $8 \mathrm{~km}$ height within less than $1 \mathrm{~h}$ (corresponding to the 25th percentile of all $\tau_{400}$ values for cyclone Sanchez) with an average ascent velocity of $11 \mathrm{~Pa} \mathrm{~s}^{-1}$ (Fig. 5). In the next 2-3 h, their cross-isentropic ascent velocity is reduced and they finish their full $600 \mathrm{hPa}$ ascent at $10 \mathrm{~km}$ height in less than $9 \mathrm{~h}$ (corresponding to the median of all $\tau_{600}$ values for cyclone Sanchez), which amounts to an averaged ascent velocity of $2 \mathrm{~Pa} \mathrm{~s}^{-1}$. Compared to WCBembedded convection of cyclone Vladiana (Oertel et al., 2020), the ascent of the moderate convective WCB trajectories is slightly slower (Fig. 5). In total, approximately 1000 WCB trajectories are selected for this sub-category.

For the composite analysis the selected WCB trajectories from both sub-categories are centered relative to the start of their fastest embedded $400 \mathrm{hPa}$ ascent phase in the lower troposphere. Subsequently, three types of composites are produced for both convective WCB sub-categories: composites of (i) horizontal and (ii) vertical cross sections centered at the trajectories' geographical position, and (iii) composites of vertical profiles along the trajectories, i.e., time-height sections along the flow.

A horizontal cross-section composite of low-level $\theta_{\mathrm{e}}$ illustrates the ascent region of the moderate convective WCB trajectories ahead of the cold front southeast of the cyclone center (Fig. 6b). The edge of the upper-level trough (PV cutoff) and the associated weak upper-level jet are located at approximately $200 \mathrm{~km}$ distance northwest of the initial trajectory ascent region (Fig. 6b). In contrast, the ascent of the intense convective WCB trajectories is located closer to the cyclone center compared to the moderate convective WCB trajectories (Fig. 6c). They ascend ahead of the cold front only about $150 \mathrm{~km}$ south of the cyclone center. When these intense convective WCB trajectories start their ascent south of $40^{\circ} \mathrm{N}$ before 10 October, the upper-level trough and accompanying polar jet are located much further north at approximately $50^{\circ} \mathrm{N}$ (Fig. 1j).

\subsection{Cloud and precipitation structure}

The cloud and precipitation structure associated with the selected WCB trajectories corroborates their convective character (Fig. 7a-d). The initial fast ascent forms a locally dense cloud with enhanced rain and snow production along the ascent (Fig. 7a, b), whereby the hydrometeor formation for the intense convective WCB trajectories is substantially larger than for the moderate convective WCB trajectories. In the mid-troposphere, between 4-7 km height, the convective ascent allows for the formation of large amounts of graupel. Due to the stronger updrafts of the intense convective WCB trajectories, the graupel production even extends to $11 \mathrm{~km}$ height (Fig. 7b). The maximum graupel water content (GWC) in the mid-troposphere at approximately $320 \mathrm{~K}$ exceeds $2.8 \mathrm{~g} \mathrm{~kg}^{-1}$ and is more than twice the maximum GWC produced by the moderate convective WCB trajectories with GWC of $1.0 \mathrm{~g} \mathrm{~kg}^{-1}$. Both sub-categories of embedded convection form a localized vertically extended dense cloud with elevated cloud top. Thereby, the ice water content peaks directly above the mean trajectory position, forming a dense cirrus shield, which is particularly dense for the intense convective WCB sub-category with IWC $>0.1 \mathrm{~g} \mathrm{~kg}^{-1}$ compared to IWC $\simeq 0.05 \mathrm{~g} \mathrm{~kg}^{-1}$ for the moderate convective subcategory. Once the WCB trajectories are located in the upper troposphere they remain inside a cirrus cloud for at least the next $6 \mathrm{~h}$. In agreement with the large hydrometeor production, the surface precipitation peaks during the strongest WCB ascent phase. The moderate convective WCB trajectories reach a maximum of $3.9 \mathrm{~mm}$ of $15 \mathrm{~min}$ accumulated surface precipitation (Fig. 7c), while for the intense convective WCB trajectories, the maximum value exceeds $6 \mathrm{~mm}$ (Fig. 7d).

The formation of a locally dense cloud with enhanced hydrometeor content, the presence of graupel in the midtroposphere and locally increased surface precipitation underlines the convective character of the selected WCB trajectories for both sub-categories. These characteristics are comparable with the previous case study of WCB-embedded convection in cyclone Vladiana (Oertel et al., 2020), where the vertically extended dense cloud was accompanied by a local precipitation peak of $4.5 \mathrm{~mm}$ of $15 \mathrm{~min}$ accumulated surface precipitation and substantial graupel production in the embedded convective updraft. The differences between both WCB sub-categories emphasizes that - similarly to the observed differences between both convective radar reflectivity cross sections (see Figs. $2 c$ and $3 b$ ) - the intensity of WCB-embedded convection can vary substantially within one WCB. This varying strength has a direct impact on the local cloud structure, the hydrometeor content, and the surface precipitation (Table 1).

\subsection{Thermodynamic properties}

Both sub-categories of convective WCB trajectories originate from an almost saturated (Fig. 7e, f), warm and moist region in the lower troposphere (Fig. 6b, c). The inflow region is characterized by a deep layer of strong potential instability with vertical $\theta_{\mathrm{e}}$ gradients between -2 and $-4 \mathrm{~K} \mathrm{~km}^{-1}$ prior to the start of the convective ascent (Fig. 7e, f). The 
(a)
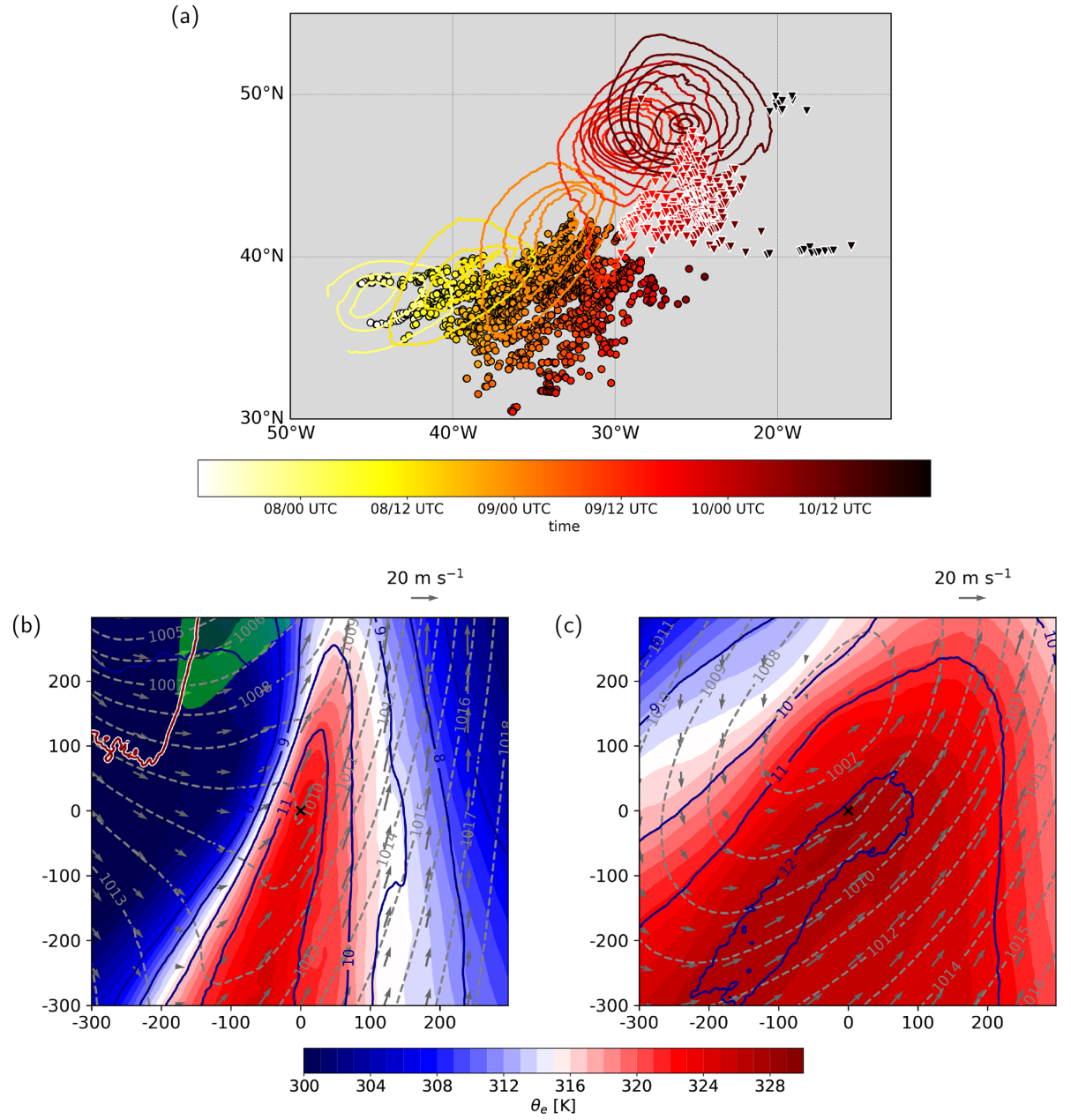

Figure 6. (a) Location of moderate convective (white outlined triangles) and intense convective (black outlined circles) WCB trajectories at the start of the fastest $400 \mathrm{hPa}$ ascent phase. Colors indicate the time of the WCB air parcel position (from 7 to 10 October 2016). Also shown is the evolution of SLP (lines are colored according to the selected times every $12 \mathrm{~h}$ from 00:00 UTC on 8 October to 12:00 UTC on 10 October). (b, c) Horizontal cross-section composites of equivalent potential temperature ( $\theta_{\mathrm{e}}$, colors, in K), specific humidity (blue contours, every $1 \mathrm{~g} \mathrm{~kg}^{-1}$ ) and wind vectors at $900 \mathrm{hPa}$ (arrows) for (b) moderate convective and (c) intense convective WCB trajectories at the start of the fastest $400 \mathrm{hPa}$ ascent. In (b) the upper-level jet (green colors, at 30 and $33 \mathrm{~m} \mathrm{~s}^{-1}$ ) and the 2 PVU contour at $320 \mathrm{~K}$ (white-red line) are also shown. The axes' dimensions denote the distance from the WCB air parcel locations marked as " $\times$ " (in km).

higher initial $\theta_{\mathrm{e}}$ of $337 \mathrm{~K}$ and the presence of stronger potential instability for the intense convective WCB trajectories enable their larger cross-isentropic ascent from 299 to $336 \mathrm{~K}(11 \mathrm{~km})$ in only $1 \mathrm{~h}$ (in agreement with their initial $\left.\theta_{\mathrm{e}}\right)$ and their faster ascent velocity compared to the moderate convective WCB trajectories with an initial $\theta_{\mathrm{e}}$ of $332 \mathrm{~K}$ and a corresponding reduced outflow level at on average $330 \mathrm{~K}(9 \mathrm{~km})$ after $6 \mathrm{~h}$. Thus, the intense convective WCB trajectories do not only reach their final height substantially faster, but their isentropic outflow level is also approximately $6 \mathrm{~K}$ higher than the outflow level of the moderate convective WCB trajectories. In contrast to the intense convective WCB trajectories, which are associated with the presence of high convective available potential energy (CAPE) values of on average $1000 \mathrm{~J} \mathrm{~kg}^{-1}$ prior to their ascent (Fig. 7h), the mod- erate convective WCB trajectories ascend in a region characterized by very low values of CAPE (Fig. 7g). The absence of high CAPE values during convective WCB ascent agrees with the previous WCB case study in cyclone Vladiana, where the WCB inflow and ascent region were characterized by comparatively low values of CAPE but substantial large-scale forcing for ascent (Oertel et al., 2019; Oertel, 2019, Fig. 4.3c).

\subsection{PV structure}

To find the characteristic upper-level PV dipole structure of WCB-embedded convection (e.g., Oertel et al., 2020), horizontal composites centered around the convective ascent are considered (Fig. 8a, b). These composites are evaluated at 
(a)

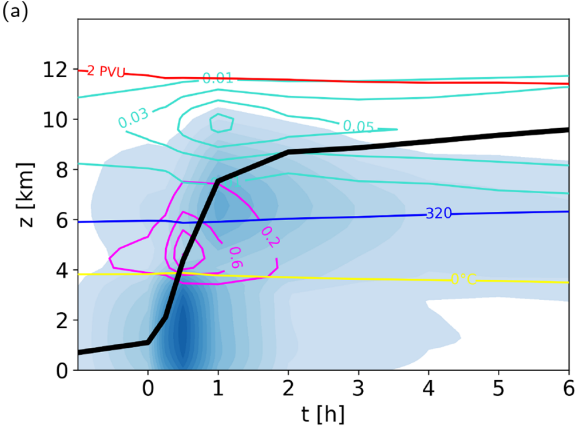

(b)

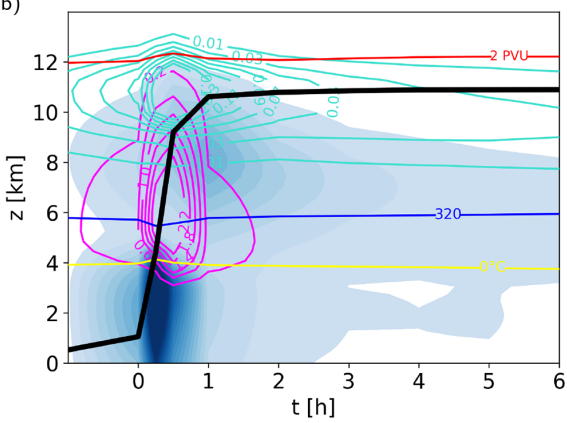

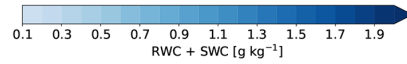

(c) 8

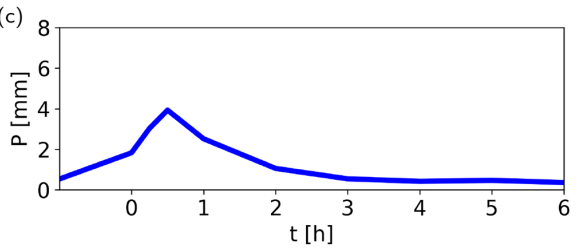

(e)

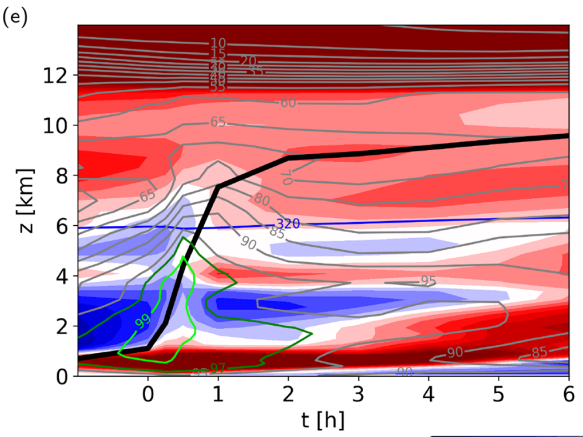

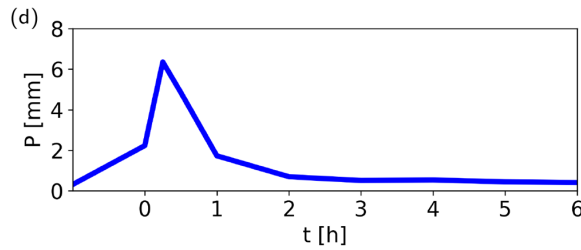

(f)

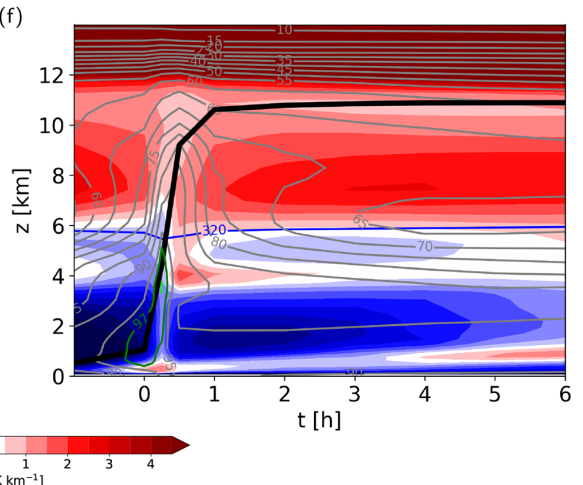

(h)
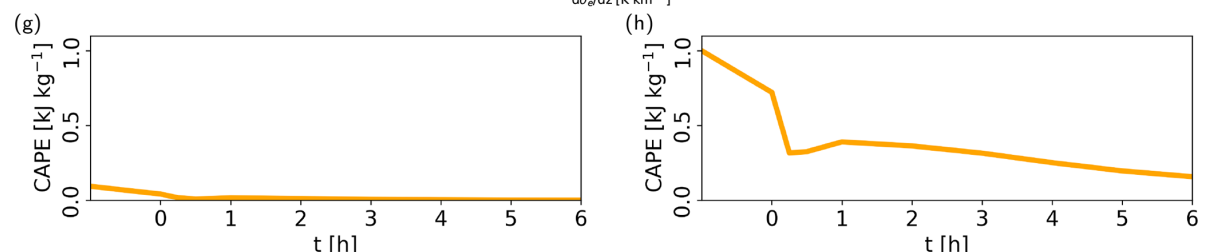

Figure 7. Composites of vertical profiles following the motion of the trajectories (black line shows the mean ascent of all WCB trajectories) for (a, $\mathbf{c}, \mathbf{e}, \mathbf{g})$ moderate and $(\mathbf{b}, \mathbf{d}, \mathbf{f}, \mathbf{h})$ intense convective WCB trajectories: (a, b) hydrometeors, i.e., sum of rain and snow water content $\left(\mathrm{RWC}+\mathrm{SWC}\right.$, colors, in $\mathrm{g} \mathrm{kg}^{-1}$ ), ice water content (IWC, turquoise contours, every $0.02 \mathrm{~g} \mathrm{~kg}^{-1}$ ), graupel water content (GWC, magenta contours, every $0.4 \mathrm{~g} \mathrm{~kg}^{-1}$ ); $0^{\circ} \mathrm{C}$ isotherm (yellow line); $320 \mathrm{~K}$ isentrope (blue line); and the $2 \mathrm{PVU}$ tropopause (red line); (c, d) $15 \mathrm{~min}$ accumulated surface precipitation along the ascent (blue, in mm); (e, f) moist stability $\left(\mathrm{d} \theta_{\mathrm{e}} / \mathrm{d} z\right.$, colors, in $\mathrm{K} \mathrm{km}^{-1}$ ), the $320 \mathrm{~K}$ isentrope (blue line), and relative humidity (RH, grey contours, in \%; $97 \%$ and $99 \%$ RH contours are highlighted in green and lime); (c, d) CAPE along the ascent (orange, in $\mathrm{kJ} \mathrm{kg}^{-1}$ ).

the $320 \mathrm{~K}$ isentrope which corresponds approximately to the level of maximum diabatic heating associated with the maximum hydrometeor content formation (which is dominated by graupel production; Fig. 7a, b). Both convective WCB subcategories form a similarly weak and small-scale horizontal PV dipole, whereby one pole reaches negative PV values. The negative PV pole with a diameter of $5-10 \mathrm{~km}$ is located to the left of the vertical wind shear vector (a more detailed discussion follows in Sect. 5.6), i.e., northeast of the ascent region for the moderate and east of the ascent region for the intense convective WCB trajectories, respectively (Fig. 8a, b).

A vertical cross section through the PV dipole for the moderate convective WCB trajectories (Fig. 8d) reveals a mid-level to upper-level PV dipole that is tilted away from the vertical and where the negative PV pole with an average magnitude of -0.3 PVU extends from 5 to $9 \mathrm{~km}$ height. The intense convective WCB trajectories form a mid-level 
Table 1. Characteristics of WCB-embedded convection for (i) moderate and (ii) intense convection in cyclone Sanchez (this study), and (iii) convection in cyclone Vladiana (Oertel et al., 2020). Shown are averaged trajectory ascent in the first hour after start of the ascent, maximum 15 min accumulated surface precipitation, maximum graupel water content (GWC), convective available energy (CAPE) prior to the ascent, mean magnitude of the negative PV pole at $320 \mathrm{~K}$ and its position relative to the convective updraft, and magnitude and direction of vertical wind shear in the middle to upper troposphere.

\begin{tabular}{llll}
\hline & $\begin{array}{l}\text { Moderate convection } \\
\text { in Sanchez }\end{array}$ & $\begin{array}{l}\text { Intense convection } \\
\text { in Sanchez }\end{array}$ & $\begin{array}{l}\text { Convection } \\
\text { in Vladiana }\end{array}$ \\
\hline $\begin{array}{l}\text { Ascent } \\
\text { Precipitation }\end{array}$ & $400 \mathrm{hPa}$ in $1 \mathrm{~h}$ & $600 \mathrm{hPa}$ in $1 \mathrm{~h}$ & $550 \mathrm{hPa}$ in $1 \mathrm{~h}$ \\
$\mathrm{GWC}$ & $3.9 \mathrm{~mm}$ & $>6 \mathrm{~mm}$ & $4.5 \mathrm{~mm}$ \\
$\mathrm{CAPE}$ & $1.0 \mathrm{~g} \mathrm{~kg}^{-1}$ & $2.8 \mathrm{~g} \mathrm{~kg}^{-1}$ & $1.8 \mathrm{~g} \mathrm{~kg}^{-1}$ \\
Negative PV pole & $-0.3 \mathrm{PVU}$ & $1000 \mathrm{~J} \mathrm{~kg}^{-1}$ & $290 \mathrm{~J} \mathrm{~kg}^{-1}$ \\
Position & northeast & $-0.2 \mathrm{PVU}$ & $-1.5 \mathrm{PVU}$ \\
Wind shear & weak & east & northwest \\
Direction & southeast & weak & strong \\
& & south & northeast \\
\hline
\end{tabular}

to upper-level PV dipole between 5-8 km height (where the negative PV pole reaches $-0.2 \mathrm{PVU}$ on average) that is located above a positive low-level PV anomaly in the lowermost $4 \mathrm{~km}$ (Fig. 8e). Compared to the moderate convective WCB sub-category, the tilted quasi-vertical PV dipole tower is slightly more pronounced, and especially the lowlevel positive $\mathrm{PV}$ anomaly is vertically more extended. ${ }^{2}$ The $\mathrm{PV}$ dipole is covered by a pronounced region of low-PV air that even includes a region of negative PV at $335 \mathrm{~K}(10 \mathrm{~km}$ height). Hence, the low-PV pole of the dipole is weaker and the negative PV is scattered in multiple elements.

Although a PV dipole forms for both sub-categories of embedded convection, the detailed PV dipole structure differs substantially from the much more pronounced PV dipole tower in cyclone Vladiana (Fig. 8c, f, and Oertel et al., 2020). To understand the differences, the main results for cyclone Vladiana by Oertel et al. (2020) are summarized in the following: embedded convection in the WCB of cyclone Vladiana, with an average ascent of $600 \mathrm{hPa}$ in $3 \mathrm{~h}$ (Fig. 5), consistently occurred in a narrow band ahead of the cold front and the upper-level trough with a strong upper-level jet of approximately $50 \mathrm{~m} \mathrm{~s}^{-1}$. Although embedded convection was weaker than the intense embedded convection in this case (Fig. 5), the convective WCB ascent formed a coherent vertically extended $\mathrm{PV}$ dipole tower between 3-9 km height with a stronger maximum amplitude of the PV dipole of $-1.5 \mathrm{PVU}$ and $3 \mathrm{PVU}$ across both poles at around $320 \mathrm{~K}$ (approximate level of maximum hydrometeor content). Moreover, the upper-level PV dipole had a larger diameter of approximately $30 \mathrm{~km}$ and was oriented from the northwest to

\footnotetext{
${ }^{2}$ The vertically extended positive low-level to mid-level PV monopole of magnitude 3.7 PVU formed by the intense convective WCB trajectories (Fig. 8d) is located near the cyclone center (Fig. 6c) and thus generates and contributes to the positive $\mathrm{PV}$ anomaly in the cyclone center potentially favoring the cyclone's maintenance and subsequent intensification (see Binder et al., 2016).
}

the southeast, with the negative PV pole to the left of the northeastward-pointing vertical wind shear vector, i.e., in the vicinity of the upper-level waveguide (Fig. 8c, f).

Hence, compared to the composite PV structure of WCBembedded convection in cyclone Vladiana (Fig. 8c, f), two major differences arise (Fig. 8): (i) in cyclone Sanchez, the upper-tropospheric PV dipole has a reduced horizontal and vertical extent and the magnitude of the PV dipole is weaker (despite faster convective ascent for the intense convective WCB trajectories in cyclone Sanchez compared to the convective WCB ascent in cyclone Vladiana), and (ii) at $320 \mathrm{~K}$, the PV dipole is oriented in the opposite direction; i.e., the negative PV pole is located northeast and east, respectively, of the convective updraft, i.e., away from the upper-level waveguide (vice versa for the PV tower in cyclone Vladiana, where the negative PV pole was located close to the upperlevel waveguide; see also Harvey et al., 2020).

The common structure in all three composites is the location of the negative PV pole to the left of the vertical wind shear vector (Fig. 8a-c). In agreement with theoretical considerations (Harvey et al., 2020; Oertel et al., 2020), the horizontal PV dipole forms if the horizontal vorticity vector $\omega_{\mathrm{h}}$ and the horizontal diabatic heating gradients $\left(\nabla_{\mathrm{h}} \dot{\theta}\right)$ are aligned, such that $\mathrm{PV}$ is produced where $\nabla_{\mathrm{h}} \dot{\theta} \| \omega_{\mathrm{h}}$ and is destroyed where $\nabla_{\mathrm{h}} \dot{\theta} \|-\omega_{\mathrm{h}}$ (see Eq. 1). Thus, the resulting PV structure is substantially governed by $\omega_{\mathrm{h}}$, which is rotated $90^{\circ}$ counterclockwise relative to the vertical wind shear vector $\mathrm{d} v / \mathrm{d} z$ and scales with $|\mathrm{d} v / \mathrm{d} z| .{ }^{3}$ The differences in the PV structure of WCB-embedded convection between both types of convective WCB ascent in cyclone Sanchez, and the PV structure of WCB-embedded convection in cyclone Vladiana (Oertel et al., 2020), are directly related to the differences in the vertical wind shear profiles and the relative

\footnotetext{
${ }^{3}$ According to Eq. (3) and neglecting the horizontal gradients of $\boldsymbol{\omega}$, we get $\boldsymbol{\omega}_{\mathrm{h}}=\left(-\frac{\mathrm{d} v}{\mathrm{~d} z}\right) \mathbf{i}+\left(\frac{\mathrm{d} u}{\mathrm{~d} z}\right) \mathbf{j}$, and $\left|\boldsymbol{\omega}_{\mathrm{h}}\right| \approx \sqrt{\left(\frac{\mathrm{d} v}{\mathrm{~d} z}\right)^{2}+\left(\frac{\mathrm{d} u}{\mathrm{~d} z}\right)^{2}}$.
} 
alignment of embedded convection and the upper-level jet. This is investigated in more detail in the next subsection.

\subsection{Vertical wind shear profiles in the convective ascent regions}

Both embedded convective regions in the WCB of cyclone Sanchez occur in a region characterized by weak vertical wind shear (Fig. 9). For the moderate convective WCB trajectories, wind speed between $1-6 \mathrm{~km}$ height is almost constant (Fig. 9a), and only above $7 \mathrm{~km}$ height does the wind speed increase result in a mean vertical wind shear of $1-$ $2 \mathrm{~m} \mathrm{~s}^{-1} \mathrm{~km}^{-1}$ that is directed towards the northeast (Fig. 9a, b). At $6 \mathrm{~km}$, the approximate level of the diabatic heating maximum (Fig. 7a), the vertical wind shear has a magnitude of approximately $1 \mathrm{~m} \mathrm{~s}^{-1} \mathrm{~km}^{-1}$, and the wind shear vector points to the southeast. Hence, the horizontal vorticity vector $\omega_{\mathrm{h}}$ rotates with height accordingly, which in turn modulates the PV modification according to $\omega_{\mathrm{h}} \cdot \nabla_{\mathrm{h}} \dot{\theta}$ and results in a northeast-southwest-oriented PV dipole at $6 \mathrm{~km}$ height (Fig. 8a, d).

For the intense convective WCB trajectories, with ascent far south of the upper-level jet, the wind speed hardly varies with height throughout almost the entire tropospheric column from 2-11 km height (Fig. 9a), resulting in very weak vertical wind shear (Fig. 9b). Indeed, between $4-8 \mathrm{~km}$ the wind speed even decreases slightly with height, such that the vertical wind shear vector points towards the south. Accordingly, the west-east-oriented PV dipole forms at $6 \mathrm{~km}$ height with negative PV to the east of the convective updraft, i.e., left of the vertical wind shear vector (Fig. 8b, e). Hence, despite stronger diabatic heating and associated stronger horizontal heating gradients $\nabla_{\mathrm{h}} \dot{\theta}$ for the intense convective WCB subcategory, the PV dipole amplitude and size is not larger compared to the moderate convective WCB sub-category due to the weak vertical wind shear in the middle to upper troposphere.

These differing vertical wind profiles result from the synoptic situation in which the convective WCB ascent is embedded. The intense convective WCB trajectories ascend in a region characterized by the absence of a strong upper-level jet (Figs. $1 \mathrm{~b}$ and $6 \mathrm{c}$ ). The upper-level wind speed hardly exceeds $20-25 \mathrm{~m} \mathrm{~s}^{-1}$, which is similar to the wind speed of the low-level jet (Fig. 9a). The moderate convective WCB trajectories ascend further north during the PV cutoff phase (Figs. 1a and 6b) and are located southeast of an upper-level jet of $30-35 \mathrm{~m} \mathrm{~s}^{-1}$ at $11 \mathrm{~km}$ height. Hence, at least in the upper troposphere, the wind speed increases leading to comparatively stronger vertical wind shear (Fig. 9a). For comparison, the northwest-southeast-oriented PV dipole of embedded convection in cyclone Vladiana (Oertel et al., 2020) with a magnitude of -1.5 and $3 \mathrm{PVU}$ across both poles is located in a region characterized by coherent unidirectional wind shear of magnitude $3 \mathrm{~m} \mathrm{~s}^{-1} \mathrm{~km}^{-1}$ in a deep layer below the upper-level jet pointing to the northeast (Fig. 9a, b). The alignment of embedded convection and the vertical wind shear in the WCB of cyclone Vladiana gives rise to the pronounced PV dipole structure with negative PV at the jetfacing side.

We conclude that the PV dipole structure associated with convective WCB ascent is strongly modulated by the largescale flow, as expected from theoretical considerations. Despite the more intense convective ascent and the associated increased localized diabatic heating, the resulting PV anomalies are not stronger in cyclone Sanchez (see Fig. 8a, b). In contrast, compared to cyclone Vladiana (Oertel et al., 2020) the associated PV anomalies of the intense convective WCB ascent in this study are weaker and the mid-level to upperlevel PV dipole extends over a smaller spatial scale - despite faster convective ascent. This implies that the upperlevel PV modification by WCB-embedded convection and its relevance for the large-scale flow evolution can differ substantially from case to case. More specifically, the comparison of the PV structures associated with cyclone Sanchez (this study) and cyclone Vladiana (Oertel et al., 2020) emphasizes that the intensity of embedded convection alone is not a reliable measure for the degree of PV modification (Table 1). Instead, the alignment of WCB-embedded convection and the upper-level jet determine the potential to produce coherent upper-level negative PV features near the jet, which were found to influence the upper-level jet and downstream flow evolution in the strong-jet situation of cyclone Vladiana (Oertel et al., 2020).

\section{Conclusions and discussion}

This study corroborates the presence of enhanced ascent phases and embedded convection in the large-scale WCB cloud band based on airborne radar observations and online trajectories from a convection-permitting simulation.

The first part of this study focuses on the identification of WCB-embedded convection with differing intensity associated with cyclone Sanchez. Overall, this study confirms the frequent occurrence of embedded convection in WCBs reported in previous case studies (e.g., Neiman et al., 1993; Crespo and Posselt, 2016; Flaounas et al., 2016; Rasp et al., 2016; Oertel et al., 2019) and illustrates the large heterogeneity of the WCB cloud band. The online trajectories from the convection-permitting simulation, airborne radar observations and satellite-based cloud top pressure qualitatively agree with respect to the strength and location of embedded convection. The main conclusions of this first part are the following.

The consideration of detailed WCB ascent in the entire cyclone suggests that intense convective ascent with $\Delta p_{2} \mathrm{~h}<$ $-600 \mathrm{hPa}$ is primarily embedded near the cyclone center and at the cold front south of $45^{\circ} \mathrm{N}$. In this region, the cloud top is heterogeneous and cloud tops locally exceed $200 \mathrm{hPa}$. Moreover, convective WCB ascent with $\Delta p_{2} \mathrm{~h}$ values be- 
(a)

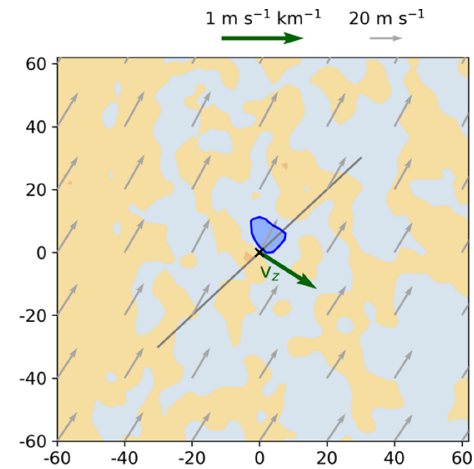

(b)

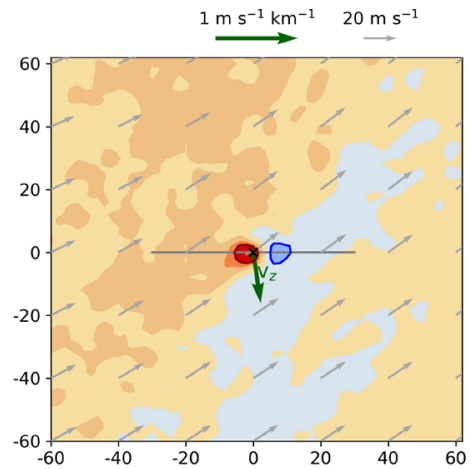

(c)

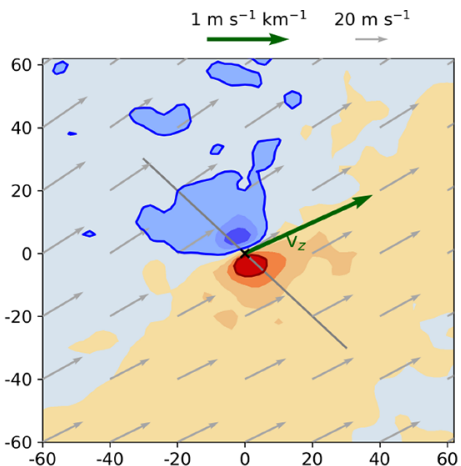

(d)

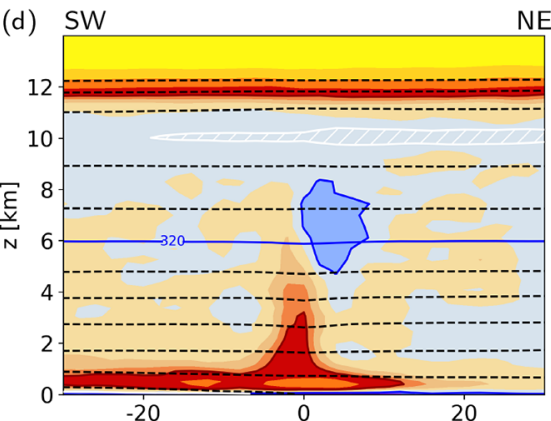

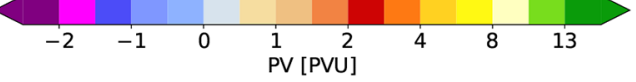

(e) W

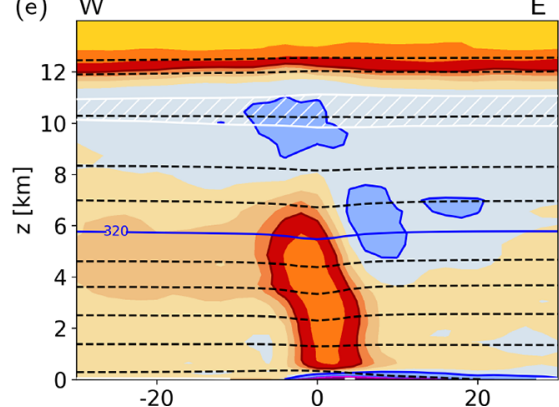

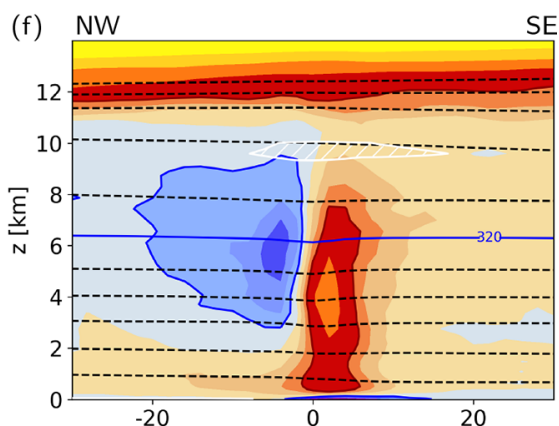

Figure 8. (a, b, c) Horizontal cross-section composites of PV (colors, in PVU) and wind speed (grey arrows, in $\mathrm{m} \mathrm{s}^{-1}$ ) at $320 \mathrm{~K}$ for (a) moderate and (b) intense convective WCB trajectories in cyclone Sanchez (a) $30 \mathrm{~min}$ after the start of the fastest $400 \mathrm{hPa}$ ascent and (b) $15 \mathrm{~min}$ after the start of the fastest $400 \mathrm{hPa}$ ascent. For comparison, (c) shows convective WCB trajectory ascent in cyclone Vladiana (Oertel et al., 2020). The green arrow shows the vertical wind shear vector $\left(\boldsymbol{v}_{z}\right)$ between 5 and $7 \mathrm{~km}$ height at the start of the WCB trajectory ascent. The axes' dimensions denote the distance from the WCB air parcel locations marked as " $x$ " (in km). (d, e, f) Vertical cross-section composites along the lines shown in (a, b, c), respectively, of PV (colors, in PVU), isentropes (dashed lines, every $5 \mathrm{~K}$ ), the $320 \mathrm{~K}$ isentrope (blue line) and low static stability layers $\left(\mathrm{d} \theta / \mathrm{d} z \leq 2 \mathrm{~K} \mathrm{~km}^{-1}\right.$, white contour and hatching). The convection-permitting simulation and Lagrangian composite analysis for cyclone Vladiana was performed in a similar way to in this study. For details see Oertel et al. (2020).

tween -350 and $-400 \mathrm{hPa}$ also occurs near the warm front and north of $45^{\circ} \mathrm{N}$ and forms an integral part of the extended WCB cloud band. The variation of the intensity of WCBembedded convection is directly reflected in the cloud structure. Airborne radar observations of stratiform and convective regions in the northern part of the WCB cloud band reveal the heterogeneous cloud structure associated with the WCB cloud band and qualitatively reflect the differing WCB ascent rates and varying degrees of embedded convection. Qualitatively, the location and intensity of embedded convection in the radar observations agree with the online trajectories. While the stratiform region of the WCB cloud band coincides with slow WCB ascent with $\Delta p_{2} \mathrm{~h}$ values of approximately $-50 \mathrm{hPa}$, the regions of embedded convection with vertically extended narrow plumes of enhanced radar reflectivity concur with $\Delta p_{2} \mathrm{~h}$ values below -350 and $-400 \mathrm{hPa}$. This also underlines the ability of the online WCB trajectories to reasonably distinguish between faster and slower convective ascent.
In the second part, the detailed ascent behavior of the WCB online trajectories is used to select two sub-categories of embedded convection: (i) moderate convective WCB trajectories with an embedded $400 \mathrm{hPa}$ ascent time below $1 \mathrm{~h}$ and (ii) intense convective WCB trajectories that perform their full $600 \mathrm{hPa}$ ascent in less than $1 \mathrm{~h}$. In this cyclone, the most intense embedded convection, with ascent rates exceeding $600 \mathrm{hPa}$ in 30-60 min, was even faster than reported in previous case studies (e.g., Rasp et al., 2016; Oertel et al., 2019, 2020; Blanchard et al., 2020). In total, approximately $10 \%$ of all WCB trajectories associated with cyclone Sanchez perform such an intense convective ascent. The fast WCB ascent velocities in this and previous case studies were related to embedded convective activity. However, for WCBs over land, fast WCB ascent and associated heavy precipitation can also be related to orographic forcing (Boettcher et al., 2020).

The systematic Lagrangian composite analysis for the intense and moderate convective WCB trajectories - and the comparison with WCB-embedded convection in cyclone 
(a)

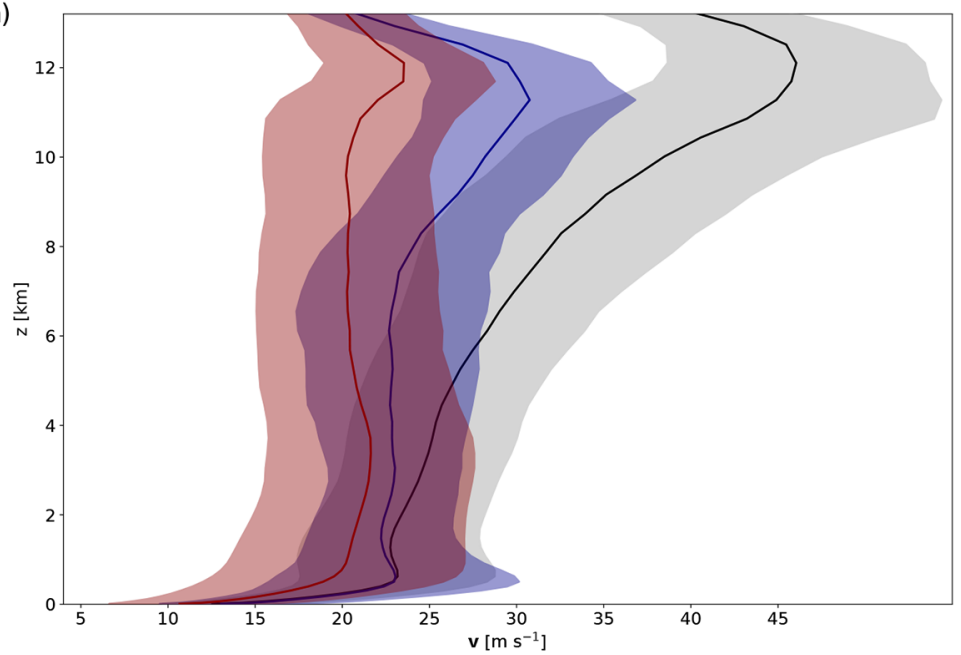

(b)

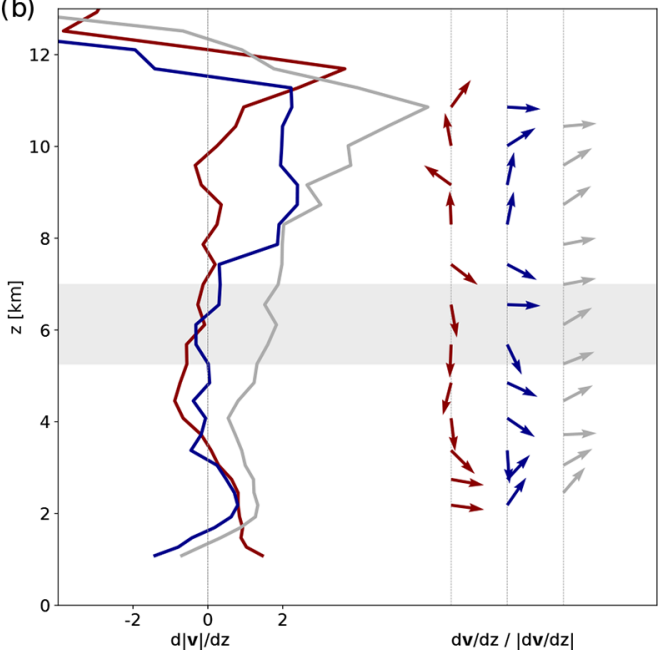

Figure 9. (a) Mean vertical profile of the horizontal wind speed ( $\mathbf{v}$, solid lines, in $\mathrm{m} \mathrm{s}^{-1}$ ) including the standard deviation (shading) in the region of convective WCB ascent for the moderate convective (blue) and intense convective (red) WCB ascent in cyclone Sanchez and for convective WCB ascent in cyclone Vladiana (grey, Oertel et al., 2020); (b) magnitude of vertical wind shear $\left(\mathrm{d}|\boldsymbol{v}| / \mathrm{d}\right.$, in $\left.\mathrm{m} \mathrm{s}^{-1} \mathrm{~km}^{-1}\right)$ and direction of the vertical shear vectors of the horizontal wind standardized by their magnitude $(\mathrm{d} v / \mathrm{d} z /|\mathrm{d} v / \mathrm{d} z|$, colored arrows) for selected altitudes. Colors as in (a). The 5-7 km layer (approximate level of $320 \mathrm{~K}$ isentrope) is outlined in grey for comparison with Fig. 8.

Vladiana (Oertel et al., 2020) with an average convective ascent of $600 \mathrm{hPa}$ in $3 \mathrm{~h}$ - highlights the direct influence of embedded convection on the cloud and precipitation structure (Table 1). The intense convective WCB ascent produces more intense surface precipitation (peak values of $15 \mathrm{~min}$ accumulated surface precipitation of $>6 \mathrm{~mm}$ compared to $3.9 \mathrm{~mm}$ for moderate convection and $4.5 \mathrm{~mm}$ for cyclone Vladiana) and larger amounts of graupel during the ascent (peak values of $>2.8 \mathrm{~g} \mathrm{~kg}^{-1}$ compared to $>1.0 \mathrm{~g} \mathrm{~kg}^{-1}$ for moderate convection and $>1.8 \mathrm{~g} \mathrm{~kg}^{-1}$ for cyclone Vladiana).

Both convective WCB sub-categories ascend from a warm and moist region in the lower troposphere ahead of the cold front. The vertical structure of $\theta_{\mathrm{e}}$ shows that moderate and intense convection both originate from a region of enhanced potential instability, but only the intense convective ascent in this study was consistently associated with higher values of CAPE prior to the onset of the convective ascent (1000 $\mathrm{J} \mathrm{kg}^{-1}$ compared to $90 \mathrm{~J} \mathrm{~kg}^{-1}$ for moderate convection and $290 \mathrm{~J} \mathrm{~kg}^{-1}$ for cyclone Vladiana).

The composite PV structure in the upper troposphere highlights the complex effects of embedded convection on the upper-level flow and PV distribution (in contrast to its rather direct impact on the cloud and precipitation structure). In agreement with the previous case study of cyclone Vladiana (Oertel et al., 2020) and theoretical considerations (Chagnon and Gray, 2009; Harvey et al., 2020), both sub-categories of WCB-embedded convection form quasi-horizontal upperlevel PV dipoles. However, we showed that the size, magnitude and orientation of the convectively generated PV dipoles - and hence their potential impact on the large-scale upperlevel flow - can differ substantially (Table 1). Compared to cyclone Vladiana, the convective ascent associated with the WCB of cyclone Sanchez is faster, but - despite the more intense convective ascent and associated latent heating - the PV dipole magnitude is lower, and its horizontal and vertical extent are smaller. Moreover, the orientation of the PV dipoles is reversed: While the negative PV pole was located west of the convective updraft near the upper-level jet in cyclone Vladiana, the negative PV pole in this study is located east of the convective updraft and away from the upper-level jet. These differences in the PV dipole formation are directly attributed to the ambient vertical wind shear (and hence the synoptic environment of the WCB), which strongly modulates the PV dipole formation and hence plays a key role for the impact of WCB-embedded convection on the upper-level flow.

This implies that the intensity of embedded convection alone is not a reliable measure for the effect of embedded convection on upper-level PV modification. Instead, the alignment of the embedded convective updraft region and the vertical wind shear vector determine the characteristics of the PV dipole. The largest potential to produce coherent upperlevel negative PV features near the jet arises if persistent convective ascent is organized in banded structures parallel to a strong upper-level jet and aligned with the vertical wind shear vector (see also Harvey et al., 2020). This emphasizes that the dynamical relevance of WCB-embedded convection does not only depend on the ascent strength (as for cloud and precipitation structure) but is strongly modulated by the synoptic situation, i.e., the location, geometry and alignment of embedded convection and the upper-level jet. 
WCBs ascend in a variety of synoptic situations associated with extratropical cyclones. Despite the limited influence of embedded convection on the upper-level flow evolution in this study, we still hypothesize that generally embedded convection in WCBs has the potential to modify the upper-level flow, because WCBs often ascend in the baroclinic environment of extratropical cyclones ahead of an upper-level jet (e.g., Binder et al., 2016; Harvey et al., 2020). Nevertheless, WCBs can also ascend with substantial distance to upper-level forcing (e.g., Binder et al., 2016), which is particularly relevant in so-called diabatic Rossby waves that are driven by low-level diabatic heating in a baroclinic environment without strong upper-level forcing (Parker and Thorpe, 1995; Boettcher and Wernli, 2013). This study suggests that the synoptic environment of the WCB co-determines the potential of embedded convection to contribute to the formation of negative PV near the upper-level jet in extratropical cyclones. Yet, the frequency of WCB-embedded convection has not been quantified climatologically. However, groundbased radar data over the United States revealed that convection frequently occurs in the warm sector and near the cold front in extratropical cyclones (Jeyaratnam et al., 2020), which coincides with regions prone to WCB ascent. Extending such analyses to other regions would be beneficial to corroborate the concept of convection embedded in extratropical cyclones in general and WCBs in particular.

Finally, this study highlights the important case-to-case variability of embedded convection in WCBs not only in terms of frequency and intensity of embedded convection but also in terms of its dynamical implications. A climatological investigation of embedded convection in WCBs using satellite observations and extended convection-permitting simulations of the extratropical storm track region would allow for a detailed quantification of the relevance of embedded convection in WCBs.

Code availability. The COSMO model code is freely available for research applications (http://www.cosmo-model.org/content/ consortium/licencing.htm; COSMO, 2021). Post-processing and analysis was performed with python.

Data availability. All data are available from the authors upon request.

Author contributions. AO performed the simulation and the data analysis and prepared a first version of the paper. $\mathrm{HK}$ and $\mathrm{MH}$ provided the calibrated radar reflectivity data. All authors continuously discussed the results and contributed to the final paper.

Competing interests. The authors declare that they have no conflict of interest.
Acknowledgements. The COSMO simulation was performed at the Swiss National Supercomputing Centre (CSCS), as part of the project sm08 (2017-2019). We thank the World Wide Lightning Location Network (http://wwlln.net, last access: January 2021), a collaboration among over 50 universities and institutions, for providing the lightning location data. We appreciate the data from EUMETSAT used to visualize the WCB cloud band. Finally, we would like to thank all the NAWDEX colleagues for the successful measurement campaign, and Derek J. Posselt and Jeffrey Chagnon for their positive and constructive feedback on our paper.

Financial support. This research has been supported by the Schweizerischer Nationalfonds zur Förderung der Wissenschaftlichen Forschung (grant no. 165941), the H2020 European Research Council (grant no. 787652), and the HALO Priority Program SPP (grant no. 1294).

Review statement. This paper was edited by Johannes Dahl and reviewed by Derek J. Posselt and Jeffrey Chagnon.

\section{References}

Abarca, S. F., Corbosiero, K. L., and Galarneau Jr., T. J.: An evaluation of the Worldwide Lightning Location Network (WWLLN) using the National Lightning Detection Network (NLDN) as ground truth, J. Geophys. Res., 115, D18206, https://doi.org/10.1029/2009JD013411, 2010.

Baldauf, M., Seifert, A., Förstner, J., Majewski, D., Raschendorfer, M., and Reinhardt, T.: Operational convective-scale numerical weather prediction with the COSMO model: Description and sensitivities, Mon. Weather Rev., 139, 3887-3905, https://doi.org/10.1175/MWR-D-10-05013.1, 2011.

Ban, N., Schmidli, J., and Schär, C.: Evaluation of the convectionresolving regional climate modeling approach in decadelong simulations, J. Geophys. Res.-Atmos., 119, 7889-7907, https://doi.org/10.1002/2014JD021478, 2014.

Bechtold, P., Köhler, M., Jung, T., Doblas-Reyes, F., Leutbecher, M., Rodwell, M. J., Vitart, F., and Balsamo, G.: Advances in simulating atmospheric variability with the ECMWF model: From synoptic to decadal time-scales, Q. J. Roy. Meteor. Soc., 134, 1337-1351, https://doi.org/10.1002/qj.289, 2008.

Bechtold, P., Semane, N., Lopez, P., Chaboureau, J.-P., Beljaars, A., and Bormann, N.: Representing equilibrium and nonequilibrium convection in large-scale models., J. Atmos. Sci., 71, 734-753, https://doi.org/10.1175/JAS-D-13-0163.1, 2014.

Bennetts, D. A. and Hoskins, B. J.: Conditional symmetric instability - a possible explanation for frontal rainbands, Q. J. Roy. Meteor. Soc., 105, 945-962, https://doi.org/10.1002/qj.49710544615, 1979.

Binder, H.: Warm conveyor belts: cloud structure and role for cyclone dynamics and extreme events, Ph.D. thesis No. 24016, ETH Zürich, available at: https://www.research-collection.ethz. ch/handle/20.500.11850/164982 (last access: January 2021), 2016.

Binder, H., Boettcher, M., Joos, H., and Wernli, H.: The role of warm conveyor belts for the intensification of extratropical cy- 
clones in Northern Hemisphere winter, J. Atmos. Sci., 73, 39974020, https://doi.org/10.1175/JAS-D-15-0302.1, 2016.

Binder, H., Boettcher, M., Joos, H., Sprenger, M., and Wernli, H.: Vertical cloud structure of warm conveyor belts - a comparison and evaluation of ERA5 reanalysis, CloudSat and CALIPSO data, Weather Clim. Dynam., 1, 577-595, https://doi.org/10.5194/wcd-1-577-2020, 2020.

Binder, H., Rivière, G., Arbogast, P., Maynard, K., Bosser, P., Joly, B., and Labadie, C.: Dynamics of forecast error growth along cut-off Sanchez and its consequence for the prediction of a highimpact weather event over southern France, Q. J. Roy. Meteor. Soc., submitted, 2020.

Blanchard, N., Pantillon, F., Chaboureau, J.-P., and Delanoë, J.: Organization of convective ascents in a warm conveyor belt, Weather Clim. Dynam., 1, 617-634, https://doi.org/10.5194/wcd-1-617-2020, 2020.

Boettcher, M. and Wernli, H.: A 10-yr climatology of diabatic Rossby waves in the Northern Hemisphere, Mon. Weather Rev., 141, 1139-1154, https://doi.org/10.1175/MWR-D-12-00012.1, 2013.

Boettcher, M., Schäfler, A., Sprenger, M., Sodemann, H., Kaufmann, S., Voigt, C., Schlager, H., Summa, D., Di Girolamo, P., Nerini, D., Germann, U., and Wernli, H.: Lagrangian matches between observations from aircraft, lidar and radar in an orographic warm conveyor belt, Atmos. Chem. Phys. Discuss. [preprint], https://doi.org/10.5194/acp-2020-1019, in review, 2020.

Browning, K.: Organisation of clouds and precipitation in extratropical cyclones, in: Extratropical cyclones. The Erik Palmén Memorial Volume, edited by: Newton, C. and Holopainen, E., pp. 129-154, Amer. Meteorol. Soc., Boston, MA, 1990.

Browning, K. A. and Roberts, N. M.: Mesoscale analysis of arc rainbands in a dry slot, Q. J. Roy. Meteor. Soc., 125, 3495-3511, 1999.

Browning, K. A., Hardman, M. E., Harrold, T. W., and Pardoe, C. W.: The structure of rainbands within a midlatitude depression, Q. J. Roy. Meteor. Soc., 99, 215-231, https://doi.org/10.1002/qj.49709942002, 1973.

Carbone, R. E.: A severe frontal rainband. Part I. Stormwide hydrodynamic structure, J. Atmos. Sci., $\quad 39, \quad 258-279, \quad$ https://doi.org/10.1175/15200469(1982)039<0258:ASFRPI>2.0.CO;2, 1982.

Chagnon, J. M. and Gray, S. L.: Horizontal potential vorticity dipoles on the convective storm scale, Q. J. Roy. Meteor. Soc., 135, 1392-1408, https://doi.org/10.1002/qj.468, 2009.

Clarke, S. J., Gray, S. L., and Roberts, N. M.: Downstream influence of mesoscale convective systems: Part 1: Influence on forecast evolution, Q. J. Roy. Meteor. Soc., 145, 2933-2952, https://doi.org/10.1002/qj.3593, 2019.

COSMO: COSMO model code, available at: http://www. cosmo-model.org/content/consortium/licencing.htm, last access: January 2021.

Crespo, J. A. and Posselt, D. J.: A-Train-based case study of stratiform - convective transition within a warm conveyor belt, Mon. Weather Rev., 144, 2069-2084, https://doi.org/10.1175/MWRD-15-0435.1, 2016.

Davis, C. A. and Weisman, M. L.: Balanced dynamics of mesoscale vortices produced in simulated convective Systems, J. Atmos. Sci., 51, 2005-2030, https://doi.org/10.1175/15200469(1994)051<2005:BDOMVP>2.0.CO;2, 1994.
Doms, G. and Baldauf, M.: A description of the non-hydrostatic regional COSMO model. Part I: Dynamics and numerics, Report COSMO-Model 5.5, Deutscher Wetterdienst, Offenbach, Germany, https://doi.org/10.5676/DWD_pub/nwv/cosmodoc_5.05_I, 2018.

ECMWF: IFS Documentation - Cy41r2: Operational implementation 8 March 2016. Dynamics and numerical procedures, ECMWF Rep., available at: https://www.ecmwf.int/en/elibrary/ 16647-part-iii-dynamics-and-numerical-procedures (last access: January 2021), 2016.

Ertel, H.: Ein neuer hydrodynamischer Wirbelsatz, Meteorol. Z., 59, 277-281, 1942.

Ewald, F., Groß, S., Hagen, M., Hirsch, L., Delanoë, J., and Bauer-Pfundstein, M.: Calibration of a $35 \mathrm{GHz}$ airborne cloud radar: lessons learned and intercomparisons with $94 \mathrm{GHz}$ cloud radars, Atmos. Meas. Tech., 12, 1815-1839, https://doi.org/10.5194/amt-12-1815-2019, 2019.

Flaounas, E., Lagouvardos, K., Kotroni, V., Claud, C., Delanoe, J., Flamant, C., Madonna, E., and Wernli, H.: Processes leading to heavy precipitation associated with two Mediterranean cyclones observed during the HyMeX SOP1, Q. J. Roy. Meteor. Soc., 142, 275-286, https://doi.org/10.1002/qj.2618, 2016.

Flaounas, E., Kotroni, V., Lagouvardos, K., Gray, S. L., Rysman, J.-F., and Claud, C.: Heavy rainfall in Mediterranean cyclones. Part 1: Contribution of deep convection and warm conveyor belt, Clim. Dynam., 50, 2935-2949, https://doi.org/10.1007/s00382017-3783-x, 2018.

Gehring, J., Oertel, A., Vignon, É., Jullien, N., Besic, N., and Berne, A.: Microphysics and dynamics of snowfall associated with a warm conveyor belt over Korea, Atmos. Chem. Phys., 20, 7373 7392, https://doi.org/10.5194/acp-20-7373-2020, 2020.

Grams, C. M., Wernli, H., Boettcher, M., Čampa, J., Corsmeier, U., Jones, S. C., Keller, J. H., Lenz, C.-J., and Wiegand, L.: The key role of diabatic processes in modifying the upper-tropospheric wave guide: a North Atlantic case-study, Q. J. Roy. Meteor. Soc., 137, 2174-2193, https://doi.org/10.1002/qj.891, 2011.

Harvey, B., Methven, J., Sanchez, C., and Schäfler, A.: Diabatic generation of negative potential vorticity and its impact on the North Atlantic jet stream, Q. J. Roy. Meteor. Soc., 146, 14771497, https://doi.org/10.1002/qj.3747, 2020.

Haynes, P. and McIntyre, M.: On the evolution of vorticity and PV in the presence of diabatic heating and frictional or other forces, J. Atmos. Sci., 44, 828-841, 1987.

Hitchman, M. H. and Rowe, S. M.: On the similarity of lowerstratospheric potential vorticity dipoles above tropical and midlatitude deep convection, J. Atmos. Sci., 74, 2593-2613, https://doi.org/10.1175/JAS-D-16-0239.1, 2017.

Hogan, R. J., Field, P. R., Illingworth, A. J., Cotton, R. J., and Choularton, T. W.: Properties of embedded convection in warm-frontal mixed-phase cloud from aircraft and polarimetric radar, Q. J. Roy. Meteor. Soc., 128, 451-476, https://doi.org/10.1256/003590002321042054, 2002.

Holloway, C. E., Petch, J. C., Beare, R. J., Bechtold, P., Craig, G. C., Derbyshire, S. H., Donner, L. J., Field, P. R., Gray, S. L., Marsham, J. H., Parker, D. J., Plant, R. S., Roberts, N. M., Schultz, D. M., Stirling, A. J., and Woolnough, S. J.: Understanding and representing atmospheric convection across scales: recommendations from the meeting held at Dartington Hall, De- 
von, UK, 28-30 January 2013, Atmos. Sci. Lett., 15, 348-353, https://doi.org/10.1002/asl2.508, 2014.

Hoskins, B.: Potential vorticity and the PV perspective, Adv. Atmos. Sci., 32, 2-9, https://doi.org/10.1007/s00376-014-0007-8, 2015.

Hoskins, B. J., McIntyre, M. E., and Robertson, A. W.: On the use and significance of isentropic potential vorticity maps, Q. J. Roy. Meteor. Soc., 111, 877-946, https://doi.org/10.1002/qj.49711147002, 1985.

Houze, R. A.: A climatological study of vertical transports by cumulus-scale convection, J. Atmos. Sci., 30, 1112-1123, https://doi.org/10.1175/15200469(1973)030<1112:ACSOVT>2.0.CO;2, 1973.

Jeyaratnam, J., Booth, J. F., Naud, C. M., Luo, Z. J., and Homeyer, C. R.: Upright convection in extratropical cyclones: A survey using ground-based radar data over the United States, Geophys. Res. Lett., 47, e2019GL086620, https://doi.org/10.1029/2019GL086620, 2020.

Joos, H. and Forbes, R. M.: Impact of different IFS microphysics on a warm conveyor belt and the downstream flow evolution, Q. J. Roy. Meteor. Soc., 142, 2727-2739, https://doi.org/10.1002/qj.2863, 2016.

Joos, H. and Wernli, H.: Influence of microphysical processes on the potential vorticity development in a warm conveyor belt: a casestudy with the limited-area model COSMO, Q. J. Roy. Meteor. Soc., 138, 407-418, https://doi.org/10.1002/qj.934, 2012.

Konow, H., Jacob, M., Ament, F., Crewell, S., Ewald, F., Hagen, M., Hirsch, L., Jansen, F., Mech, M., and Stevens, B.: HALO Microwave Package measurements during North Atlantic Waveguide and Downstream impact EXperiment (NAWDEX), World Data Center for Climate (WDCC) at DKRZ, https://doi.org/10.1594/WDCC/HALO_measurements_4, 2018.

Konow, H., Jacob, M., Ament, F., Crewell, S., Ewald, F., Hagen, M., Hirsch, L., Jansen, F., Mech, M., and Stevens, B.: A unified data set of airborne cloud remote sensing using the HALO Microwave Package (HAMP), Earth Syst. Sci. Data, 11, 921-934, https://doi.org/10.5194/essd-11-921-2019, 2019.

Madonna, E., Wernli, H., Joos, H., and Martius, O.: Warm conveyor belts in the ERA-Interim dataset (1979-2010). Part I: Climatology and potential vorticity evolution, J. Climate, 27, 3-26, https://doi.org/10.1175/JCLI-D-12-00720.1, 2014.

Martínez-Alvarado, O., Gray, S. L., and Methven, J.: Diabatic processes and the evolution of two contrasting summer extratropical cyclones, Mon. Weather Rev., 144, 3251-3276, https://doi.org/10.1175/MWR-D-15-0395.1, 2016.

Mech, M., Orlandi, E., Crewell, S., Ament, F., Hirsch, L., Hagen, M., Peters, G., and Stevens, B.: HAMP - the microwave package on the High Altitude and LOng range research aircraft (HALO), Atmos. Meas. Tech., 7, 4539-4553, https://doi.org/10.5194/amt7-4539-2014, 2014.

Melchiona, S., Bauer, M., and Peters, G.: A new algorithm for the extraction of cloud parameters using multipeak analysis of cloud radar data - First application and preliminary results, Meteorol. Z., 17, 613-620, 2008.

Methven, J.: Potential vorticity in warm conveyor belt outflow, Q. J. Roy. Meteor. Soc., 141, 1065-1071, https://doi.org/10.1002/qj.2393, 2015.

Miller, L. J., Tuttle, J. D., and Knight, C. A.: Airflow and hail growth in a severe Northern High Plains supercell,
J. Atmos. Sci., 45, 736-762, https://doi.org/10.1175/1520 0469(1988)045<0736:AAHGIA>2.0.CO;2, 1988.

Miltenberger, A. K., Pfahl, S., and Wernli, H.: An online trajectory module (version 1.0) for the nonhydrostatic numerical weather prediction model COSMO, Geosci. Model Dev., 6, 1989-2004, https://doi.org/10.5194/gmd-6-1989-2013, 2013.

Miltenberger, A. K., Roches, A., Pfahl, S., and Wernli, H.: Online trajectory module in COSMO: A short user guide, Consortium for Small-scale Modelling, COSMO Technical Report 24, available at: http://www.cosmo-model.org/content/ model/documentation/techReports/default.htm (last access: January 2021), 2014.

Müller, A., Niedrich, B., and Névir, P.: Three-dimensional potential vorticity structures for extreme precipitation events on the convective scale, Tellus A, 72, 1-20, https://doi.org/10.1080/16000870.2020.1811535, 2020.

Murphy, A. M., Rauber, R. M., McFarquhar, G. M., Finlon, J. A., Plummer, D. M., Rosenow, A. A., and Jewett, B. F.: A microphysical analysis of elevated convection in the comma head region of continental winter cyclones, J. Atmos. Sci., 74, 69-91, https://doi.org/10.1175/JAS-D-16-0204.1, 2017.

Naud, C., Posselt, D., and van den Heever, S.: A CloudSatCALIPSO view of cloud and precipitation properties across cold fronts over the global oceans, J. Climate, 28, 6743-6762, https://doi.org/10.1175/JCLI-D-15-0052.1, 2015.

Neiman, P. J., Shapiro, M. A., and Fedor, L. S.: The life cycle of an extratropical marine cyclone. Part II: Mesoscale structure and diagnostics, Mon. Weather Rev., 121, 2177-2199, https://doi.org/10.1175/1520 0493(1993)121<2177:TLCOAE>2.0.CO;2, 1993.

Oertel, A.: Embedded convection in warm conveyor belts, Ph.D. thesis No. 26554, ETH Zürich, Zürich, Switzerland, https://doi.org/10.3929/ethz-b-000414750, 2019.

Oertel, A. and Schemm, S.: Quantifying the circulation induced by convective clouds in kilometer-scale simulations, Q. J. Roy. Meteor. Soc., submitted, 2020.

Oertel, A., Boettcher, M., Joos, H., Sprenger, M., Konow, H., Hagen, M., and Wernli, H.: Convective activity in an extratropical cyclone and its warm conveyor belt - a casestudy combining observations and a convection-permitting model simulation, Q. J. Roy. Meteor. Soc., 145, 1406-1426, https://doi.org/10.1002/qj.3500, 2019.

Oertel, A., Boettcher, M., Joos, H., Sprenger, M., and Wernli, H.: Potential vorticity structure of embedded convection in a warm conveyor belt and its relevance for large-scale dynamics, Weather Clim. Dynam., 1, 127-153, https://doi.org/10.5194/wcd-1-1272020, 2020.

Parker, D. J. and Thorpe, A. J.: Conditional convective heating in a baroclinic atmosphere: A model of convective frontogenesis, J. Atmos. Sci., 52, 1699-1711, https://doi.org/10.1175/15200469(1995)052<1699:CCHIAB>2.0.CO;2, 1995.

Pomroy, H. R. and Thorpe, A. J.: The evolution and dynamical role of reduced upper-tropospheric potential vorticity in intensive observing period one of FASTEX, Mon Weather Rev., 128, 1817-1834, https://doi.org/10.1175/15200493(2000)128<1817:TEADRO>2.0.CO;2, 2000.

Rasp, S., Selz, T., and Craig, G.: Convective and slantwise trajectory ascent in convection-permitting simulations of 
midlatitude cyclones, Mon. Weather Rev., 144, 3961-3976, https://doi.org/10.1175/MWR-D-16-0112.1, 2016.

Rodwell, M., Forbes, R., and Wernli, H.: Why warm conveyor belts matter in NWP, ECMWF Newsletter, European Centre for Medium-Range Weather Forecasts, Reading, England, 154, 2128, https://doi.org/10.21957/mr20vg, 2017.

Schäfler, A., Craig, C., Wernli, H., Arbogast, P., Doyle, J. D., McTaggart-Cowan, R., Methven, J., Rivière, G., Ament, F., Boettcher, M., Bramberger, M., Cazenave, Q., Cotton, R., Crewell, S., Delanoë, J., Dörnbrack, A., Ehrlich, A., Ewald, F., Fix, A., Grams, C. M., Gray, S. L., Grob, H., Groß, S., Hagen, M., Harvey, B., Hirsch, L., Jacob, M., Kölling, T., Konow, H., Lemmerz, C., Lux, O., Magnusson, L., Mayer, B., Mech, M., Moore, R., Pelon, J., Quinting, J., Rahm, S., Rapp, M., Rautenhaus, M., Reitebuch, O., Reynolds, C. A., Sodemann, H., Spengler, T., Vaughan, G., Wendisch, M., Wirth, M., Witschas, B., Wolf, K., and Zinner, T.: The North Atlantic Waveguide and Downstream Impact Experiment, B. Am. Meteorol. Soc., 99, 16071637, https://doi.org/10.1175/BAMS-D-17-0003.1, 2018.

Schindler, M., Weissmann, M., Schäfler, A., and Radnoti, G.: The impact of dropsonde and extra radiosonde observations during NAWDEX in autumn 2016, Mon. Weather Rev., 148, 809-824, https://doi.org/10.1175/MWR-D-19-0126.1, 2020.

Schmetz, J., Pili, P., Tjemkes, S., Just, D., Kerkmann, J., Rota, S., and Ratier, A.: An Introduction to Meteosat Second Generation (MSG), B. Am. Meteorol. Soc., 83, 977-992, https://doi.org/10.1175/15200477(2002)083<0977:AITMSG>2.3.CO;2, 2002.

Schultz, D. M. and Schumacher, P. N.: The use and misuse of conditional symmetric instability, Mon. Weather Rev., 127, 2709-2732, https://doi.org/10.1175/15200493(1999)127<2709:TUAMOC>2.0.CO;2, 1999.
Sherwood, S. C., Bony, S., and Dufresne, J.-L.: Spread in model climate sensitivity traced to atmospheric convective mixing, Nature, 505, 37-42, https://doi.org/10.1038/nature12829, 2014.

Steiner, M., Houze Jr., R. A., and Yuter, S. E.: Climatological characterization of three-Dimensional storm structure from operational radar and rain gauge data, J. Appl. Meteor., 34, 1978-2007, https://doi.org/10.1175/15200450(1995)034<1978:CCOTDS>2.0.CO;2, 1995.

Tiedtke, M.: A comprehensive mass flux scheme for cumulus parameterization in large-scale models, Mon. Weather Rev., 117, 1779-1800, https://doi.org/10.1175/15200493(1989)117<1779:ACMFSF>2.0.CO;2, 1989.

Volonté, A., Clark, P. A., and Gray, S. L.: Idealised simulations of cyclones with robust symmetrically unstable sting jets, Weather Clim. Dynam., 1, 63-91, https://doi.org/10.5194/wcd1-63-2020, 2020.

Weijenborg, C., Friederichs, P., and Hense, A.: Organisation of potential vorticity on the mesoscale during deep moist convection, Tellus, 67, 25705, https://doi.org/10.3402/tellusa.v67.25705, 2015.

Weijenborg, C., Chagnon, J. M., Friederichs, P., Gray, S. L., and Hense, A.: Coherent evolution of potential vorticity anomalies associated with deep moist convection, Q. J. Roy. Meteor. Soc., 143, 1254-1267, https://doi.org/10.1002/qj.3000, 2017.

Wernli, H. and Davies, H. C.: A Lagrangian-based analysis of extratropical cyclones. I: The method and some applications, Q. J. Roy. Meteor. Soc., 123, 467-489, https://doi.org/10.1256/smsqj.53810, 1997. 